\title{
Sex differences in psychophysical and neurophysiological responses to pain in older adults: a cross-sectional study
}

Todd B. Monroe ${ }^{*}$, John C. Gore ${ }^{2}$, Stephen P. Bruehl ${ }^{3}$, Margaret M. Benningfield ${ }^{4}$, Mary S. Dietrich ${ }^{4}$, Li Min Chen ${ }^{2}$, Paul Newhouse ${ }^{5}$, Roger Fillingim ${ }^{6}$, BettyAnn Chodkowski ${ }^{4}$, Sebastian Atalla', Julian Arrieta ${ }^{1}$, Stephen M. Damon ${ }^{7}$, Jennifer Urbano Blackford ${ }^{4}$ and Ronald L. Cowan ${ }^{4}$

\begin{abstract}
Background: Neuroimaging studies in younger adults have demonstrated sex differences in brain processing of painful experimental stimuli. Such differences may contribute to findings that women suffer disproportionately from pain. It is not known whether sex-related differences in pain processing extend to older adults.

Methods: This cross-sectional study investigated sex differences in pain reports and brain response to pain in 12 cognitively healthy older female adults and 12 cognitively healthy age-matched older male adults (age range $65-81$, median $=67$ ). Participants underwent psychophysical assessments of thermal pain responses, functional MRI, and psychosocial assessment.

Results: When compared to older males, older females reported experiencing mild and moderate pain at lower stimulus intensities (i.e., exhibited greater pain sensitivity; Cohen's $d=0.92$ and 0.99 , respectively, $p<0.01$ ) yet did not report greater pain-associated unpleasantness. Imaging results indicated that, despite the lower stimulus intensities required to elicit mild pain detection in females, they exhibited less deactivations than males in regions associated with the default mode network (DMN) and in regions associated with pain affect (bilateral dorsolateral prefrontal cortex, somatomotor area, rostral anterior cingulate cortex (rACC), and dorsal ACC). Conversely, at moderate pain detection levels, males exhibited greater activation than females in several ipsilateral regions typically associated with pain sensation (e.g., primary (SI) and secondary somatosensory cortices (SII) and posterior insula). Sex differences were found in the association of brain activation in the left rACC with pain unpleasantness. In the combined sample of males and females, brain activation in the right secondary somatosensory cortex was associated with pain unpleasantness.
\end{abstract}

Conclusions: Cognitively healthy older adults in the sixth and seventh decades of life exhibit similar sex differences in pain sensitivity compared to those reported in younger individuals. However, older females did not find pain to be more unpleasant. Notably, increased sensitivity to mild pain in older females was reflected via less brain deactivation in regions associated with both the DMN and in pain affect. Current findings elevate the rACC as a key region associated with sex differences in reports of pain unpleasantness and brain deactivation in older adults. Also, pain affect may be encoded in SII in both older males and females.

Keywords: Functional MRI, Pain, Older adults, Sex differences, Psychophysics, Thermal pain, Neuroimaging

\footnotetext{
* Correspondence: todd.b.monroe@Vanderbilt.Edu

'Vanderbilt Psychiatric Neuroimaging Program, Vanderbilt University School

of Nursing, Vanderbilt University Institute of Imaging Science, Nashville, TN,

USA

Full list of author information is available at the end of the article
}

C Biomed Central (c) 2015 Monroe et al. Open Access This article is distributed under the terms of the Creative Commons Attribution 4.0 International License (http://creativecommons.org/licenses/by/4.0/), which permits unrestricted use, distribution, and reproduction in any medium, provided you give appropriate credit to the original author(s) and the source, provide a link to the Creative Commons license, and indicate if changes were made. The Creative Commons Public Domain Dedication waiver (http://creativecommons.org/publicdomain/zero/1.0/) applies to the data made available in this article, unless otherwise stated. 


\section{Background}

Pain is the primary reason that people seek medical attention [1]. Chronic pain affects one-quarter of the world's population, and the prevalence of chronic pain increases with age [2]. This increased risk of pain in aging appears to be compounded by age-related declines in the function of endogenous pain inhibitory systems [3-5]. In addition to the increased risk of pain associated with aging, sex differences in pain risk have been reported [6], with women generally reporting a higher prevalence of chronic pain that increases with age $[7,8]$. In a large-scale study of pain reports in males and females, females reported higher pain intensity scores than males for comparable pain conditions [9].

Central pain processing is classically described in basic neural circuits comprising the "pain matrix" consisting of the sensory/discriminative, affective/motivational, and cognitive/evaluative networks [10-13]. In brief, the sensory/discriminative (sometimes referred to as the lateral) pathway includes the ventral posterolateral (VPL), thalamic nucleus, and primary (SI) and secondary (SII) somatosensory cortices. The affective/motivational and cognitive/ evaluative components of pain are typically included in the (medial) pathway and include the dorsomedial (DM) thalamic nucleus, the dorsolateral prefrontal cortex (dlPFC), the insula (INS), and the anterior cingulate cortex (ACC; Fig. 1). While the INS cortex is generally included in the affective/motivational pathway, the role of the INS in salience detection and executive function is quite complex [14] and should deservedly be described with functions in multiple pain networks. The anterior INS (aINS) is associated with relaying affective information [15], while the posterior INS (pINS) is associated with the detection of pain sensation and discrimination [16]. Emerging evidence from human neuroimaging studies suggests that a much broader array of brain regions than those classically included in the "pain matrix" are important to the pain experience and that these pain networks do not function independently [17-19].

In addition to the abovementioned sex differences in the clinical experience of pain, psychophysical studies of responses to experimental thermal pain stimuli in younger adults suggest sex differences. In these studies, females generally exhibit lower pain threshold and lower pain tolerance levels, while commonly rating pain

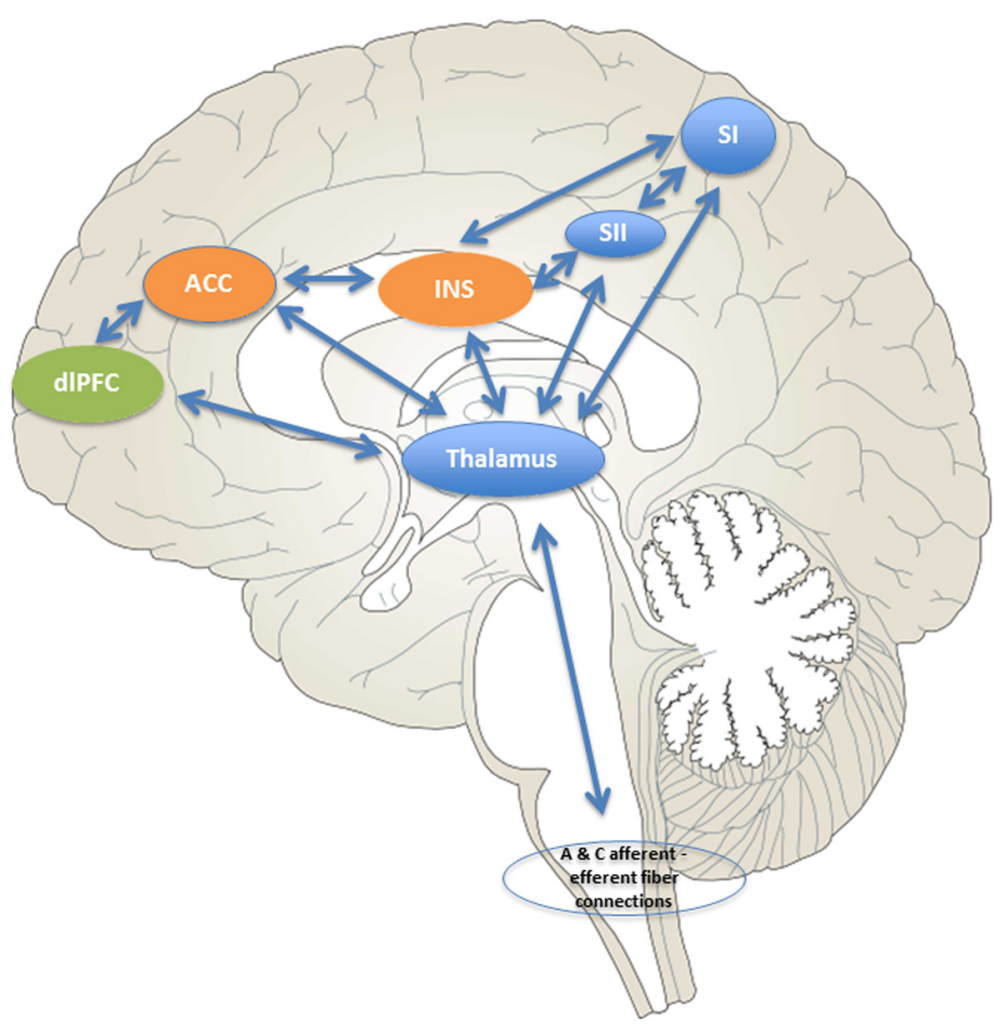

Fig. 1 Basic pain matrix model. Basic structures of the "pain matrix." Blue areas represent common structures in the sensory/discriminative (lateral) pain pathway (thalamus, SI, SII). Orange areas represent common structures identified in the affective/motivational (medial) pain pathway (ACC, INS). The green region represents one component of the cognitive/evaluative pain system (dIPFC). The arrows represent multiple cortical connections between regions and systems indicating the complex interconnectedness of brain regions involved with pain. ACC anterior cingulate cortex, INS insula, dIPFC dorsolateral prefrontal cortex, SI primary somatosensory cortex, SII secondary somatosensory cortex 
to be more intense and more unpleasant than do males (reviewed in [6]). Functional neuroimaging studies examining the neurophysiological basis of sex differences in pain processing have generally been restricted to younger cohorts (i.e., those under 65 years of age). These studies have revealed a variety of sex-related differences in brain activation during experimental pain delivery $[20,21]$. A recent study found that in younger adults, functional connectivity (FC) differed by sex with women demonstrating greater FC between the subgenual ACC (sgACC) and several regions modulating descending pain, whereas men demonstrated greater FC between the sgACC and several regions implicated in sustained attention to pain, potentially delaying descending modulation [22].

Since there are limited reports of sex-associated differences in the psychophysical and neurophysiological processing of pain in older adults (i.e., those 65 years of age and older), the aim of the current study was to examine sex differences in both psychophysical (as measured with verbal pain reports) and neurophysiological (as measured by brain activation) responses to standardized (perceptually matched) experimental thermal heat pain in healthy older adults. Based on existing literature in younger cohorts, our first hypothesis (psychophysical) was that, when compared to older males, older females would report "mild" and "moderate" pain at lower stimulus intensities (i.e., be more pain sensitive) and would report greater perceived pain unpleasantness even with no sex difference in perceived pain intensity. Our second hypothesis (neurophysiological) was that, when compared to older males, older females would exhibit greater brain activations in the sensory/discriminative, affective/ motivational, and cognitive/evaluative pain networks in response to experimental thermal pain delivery.

\section{Methods}

This cross-sectional study was approved by the Vanderbilt University Institutional Review Board, and each participant provided written informed consent at the time of enrollment. From an ongoing study on pain in dementia, 24 age-matched healthy volunteers (12 men, 12 women) aged 65 to 81 years with a median age of 67 years were selected for the analyses of sex differences.

\section{Screening and enrollment of participants}

Participants were recruited from the Nashville, Tennessee, metropolitan area using mass email, flyers, and recruitment presentations in facilities (e.g., assisted living facilities, retirement homes, and adult day care services) and at local events such as healthy aging seminars. A two-part screening process included an initial telephone screening followed by a 1-h consenting/enrollment visit scheduled at the participant's place of residence (e.g., home or independent living facility). During the consenting/enrollment visit, a trained research assistant verified inclusion and exclusion criteria. Participants were excluded for the following reasons: presence of chronic pain diagnosis, cognitive impairment (score $\leq 28$ on Mini-Mental State Exam (MMSE) [23]), regular use of opioid or non-opioid pain medication, history of stroke, cancer, peripheral neuropathy, Raynaud's Disease, unstable cardiac conditions, insulin dependent diabetes, hormone replacement therapy (females), or a current diagnosis of major depression. Magnetic resonance imaging (MRI) exclusion criteria were claustrophobia; presence of pacemaker, ventricular shunt, or any implanted metal object that could not be confirmed as 3 Tesla ( $3 \mathrm{~T}$ ) MRI compatible; multiple metal implants in the same extremity; or presence of movement disorders such as Parkinson's disease, restless leg syndrome, or essential tremor. Since hormone replacement therapy has been shown to increase experimental pain thresholds in females [24], we excluded participants who were prescribed hormone replacement therapy. Socioeconomic status (SES) may also impact the experience and reporting of pain [25]; therefore, the groups were matched on SES. All participants were instructed to avoid drinking caffeine for $4 \mathrm{~h}$ before scanning and not to use any pain medication (opioid or non-opioid) for at least $24 \mathrm{~h}$ prior to data collection. Participants were reimbursed $\$ 100.00$ for their time.

\section{Assessments}

Participants underwent $1 \mathrm{~h}$ of psychosocial assessments during the home visit. These included a detailed list of all regularly scheduled and pro re nata medications, demographic information, Hollingshead Four-Factor SES [26], MRI safety clearance, and cognitive screening with both the MMSE [23] and the dementia rating scale (DRS) [27]. On the day of the MRI procedures, each subject was further assessed with the Brief Pain Inventory (BPI) [28], Geriatric Depression Scale (GDS) [29], and State-Trait Anxiety Inventory (STAI) [30].

\section{Thermal stimulation protocol (psychophysics)}

Since the current study was part of a larger study on pain in people with and without dementia, the thermal stimulation protocol used in this study was a modification of the experimental mechanical pressure pain protocol used successfully by Cole and colleagues to examine psychophysical responses and brain activations in people with Alzheimer's disease [31]. Upon arrival at the Vanderbilt University Institute of Imaging Science, participants underwent a thermal pain psychophysics evaluation ( 30 min) followed by one MRI session ( $\sim 0 \mathrm{~min})$. Pain psychophysics were assessed using the Medoc Pathway Pain and Sensory Evaluation System [32] in a room adjacent to the MRI scanner. The Medoc thermode $(30 \times 30 \mathrm{~mm})$ was attached to the thenar eminence of the right hand.

Before beginning sensory threshold testing, participants were told, "There are two aspects of pain which we are interested in measuring: the intensity, how strong the pain feels, and the unpleasantness, how unpleasant 


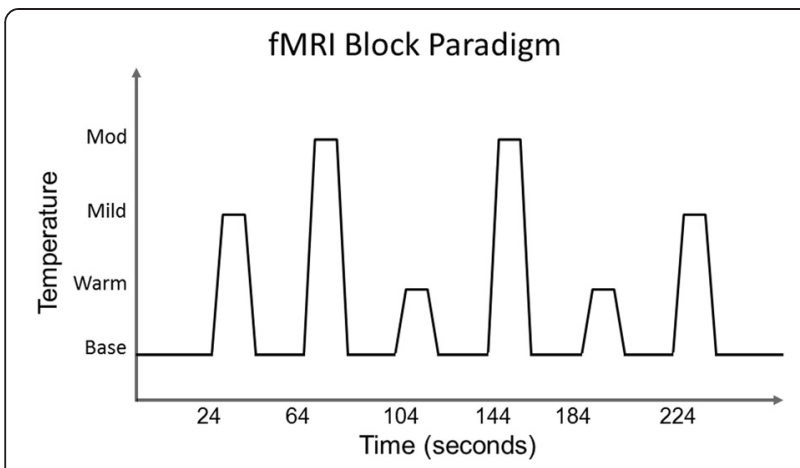

Fig. 2 fMRI paradigm. Graphical depiction of experimental paradigm design demonstrating timing of pseudo-randomly delivered thermal stimuli during four functional MRI scans. Not to scale. Scan time 264 s per functional run or disturbing the pain is for you" [33]. Next, participants were shown a $0-20$ sensory pain intensity scale used in prior work [32], which included the anchors "warmth $=0$," "mild pain $=5$," and "moderate pain $=11$." Additionally, each participant was read the following: "I will tell you when the metal cube that is attached to your hand will start heating up, then I will ask you to stop the heat when you feel 'warmth,' 'mild pain, or 'moderate pain.' I will not ask you to rate any pain greater than 'moderate pain.' An example of 'mild pain' might be the temperature of a hot bath and an example of 'moderate pain' might be the temperature of a fresh hot cup of coffee." Next, participants were shown a parallel 0-20 unpleasantness scale with the following anchor descriptions: " $0=$ neutral," " $5=$ slightly unpleasant," " $8=$ unpleasant," " $11=$ very unpleasant," "16 = intolerable," and " $20=$ extremely

Table 1 Demographic and clinical summaries by sex

\begin{tabular}{|c|c|c|c|c|}
\hline & Total $(N=24)$ & Female $(N=12)$ & Male $(N=12)$ & $p$ value \\
\hline & Median (IQR) & Median (IQR) & Median (IQR) & \\
\hline Age & $66.5(65,69)$ & $67.0(65,70)$ & $66.5(66,69)$ & 0.724 \\
\hline Race & $N(\%)$ & $N(\%)$ & $N(\%)$ & 0.218 \\
\hline Caucasian & $21(87.5)$ & $10(83.3)$ & $11(91.7)$ & \\
\hline African-American & $2(8.3)$ & $2(16.7)$ & $0(0.0)$ & \\
\hline Asian & $1(4.2)$ & $0(0.0)$ & $1(8.3)$ & \\
\hline Marital status & & & & 0.206 \\
\hline Married & $15(62.5)$ & $6(50.0)$ & $9(75.0)$ & \\
\hline Not married & $9(37.5)$ & $6(50.0)$ & $3(25.0)$ & \\
\hline Marital occupational status & & & & 0.102 \\
\hline One spouse gainfully employed & $12(50.0)$ & $8(66.7)$ & $4(33.3)$ & \\
\hline Both spouses gainfully employed & $12(50.0)$ & $4(33.3)$ & $8(66.7)$ & \\
\hline Level of school completed & & & & 0.241 \\
\hline High school & $3(12.5)$ & $3(25.0)$ & $0(0.0)$ & \\
\hline Technical/some college & $8(33.3)$ & $3(25.0)$ & $5(41.7)$ & \\
\hline College graduate & $5(20.8)$ & $3(25.0)$ & $2(16.7)$ & \\
\hline Advanced degree & $8(33.3)$ & $3(25.0)$ & $5(41.7)$ & \\
\hline \multicolumn{5}{|l|}{ Standardized measures } \\
\hline$B M l^{\mathrm{a}}$ & $27.4(23,30)$ & $25.1(23,29)$ & $28.1(25,30)$ & 0.133 \\
\hline Total SES score ${ }^{b}$ & $56.3(45,66)$ & $57.5(35,64)$ & $55.5(45,66)$ & 0.560 \\
\hline MMSE score ${ }^{c}$ & $30.0(29,30)$ & $30.0(28,30)$ & $30.0(29,30)$ & 0.641 \\
\hline BPI-SF average pain ${ }^{d}$ & $1.0(0,2)$ & $2.0(0,3)$ & $1.0(0,2)$ & 0.512 \\
\hline BPI-SF pain right now ${ }^{d}$ & $0.0(0,1)$ & $0.0(0,0)$ & $0.0(0,1)$ & 0.403 \\
\hline GDS-SF score & $0.0(0,2)$ & $0.0(0,2)$ & $0.5(0,2)$ & 0.425 \\
\hline STAl state score ${ }^{f}$ & $48.5(45,51)$ & $50.0(45,53)$ & $47.0(44,50)$ & 0.117 \\
\hline STAI trait score ${ }^{f}$ & $47.5(45,51)$ & $49.5(46,53]$ & $46.5(43,49]$ & 0.068 \\
\hline
\end{tabular}

${ }^{\mathrm{a}} \mathrm{BMI}=$ body mass index

${ }^{\mathrm{b} H o l l i n g s h e a d ~ F o u r-F a c t o r ~ M e a s u r e ~ o f ~ S o c i o e c o n o m i c ~ S t a t u s ~(r a n g e ~}=8-66 ; 8=$ lowest SES, $66=$ highest SES)

${ }^{c}$ MMSE-Folstein Mini-Mental State Examination (range $=0-30 ; 0=$ completely cognitively impaired, $30=$ completely cognitively intact)

dBPI-SF-Brief Pain Inventory Short Form (range $=0-10 ; 0=$ no pain, $10=$ most pain)

${ }^{\mathrm{e}} \mathrm{GDS}-\mathrm{SF}-$ Geriatric Depression Scale Short Form (range; $0=$ no indication of depression, $15=$ high possibility of depression)

${ }^{f}$ STAI-Spielberger State or Trait Anxiety Inventory (range; $20=$ indicates increased anxiety, $80=$ indicates least amount of anxiety) 
distressing" [32]. Instructions given for these ratings were "After you stop the heat, I will ask you to tell me how unpleasant the previous temperature was."

We defined the baseline temperature as $30{ }^{\circ} \mathrm{C}$ (a temperature not perceived as warm or cold [34]) and programmed the thermode to deliver heat increasing at a rate of $4{ }^{\circ} \mathrm{C} / \mathrm{s}$. We modeled our thermal stimulus delivery after Wager and colleague's successful paradigm in which each instance of a temperature began from baseline and ramped up and down at a moderate rate [19]. Subsequently, we recorded the temperature at which each participant reported the sensations of warmth, mild pain, and moderate pain. Each participant completed three trials at each temperature condition. The average temperature (in degrees Celsius) across the trials at each level of intensity was used in analyses ( $\max$ temperature $\left.=48{ }^{\circ} \mathrm{C}\right)$. Immediately after indicating the first stimulus meeting criteria for each of the three intensity levels, participants were asked to rate the unpleasantness associated with that stimulus level (i.e., warmth, mild pain, and moderate pain) as described above.

\section{Brain imaging acquisition: structural and functional}

Brain images were acquired on a Philips 3T Achieva MRI scanner (Philips Healthcare Inc., Best, Netherlands). A standard whole-brain 3-D anatomical T1-weighted/time of flight echo (TFE with SENSE coil) scan was acquired. In each 264-s-duration functional run, 28 field echo planar imaging (EPI) (162 dynamics, 4.50-mm slice thickness with $0.45-\mathrm{mm}$ gap, 2 -s time to repeat (TR), 35-ms echo time (TE), $79^{\circ}$ flip angle, field of view $(\mathrm{FOV})=240$, matrix $=128 \times 128)$ scans were acquired.

\section{Thermal stimulation protocol (fMRI)}

During functional MRI (fMRI), heat pain stimulation was administered to the thenar eminence of the right hand using the same Medoc pathways system described above. Prior to scanning procedures, the Medoc was

Table 2 Summary of psychophysics of temperature thresholds necessary to produce ratings at each condition

\begin{tabular}{|c|c|c|c|c|c|c|c|}
\hline Variables & & Min & Max & Median & IQR & $p$ value $^{a}$ & Effect size $^{\mathrm{b}}$ \\
\hline \multicolumn{8}{|l|}{ Temperature } \\
\hline \multirow[t]{2}{*}{ Warmth } & Males & 31 & 38 & 33.0 & $32.0-33.0$ & 0.186 & 0.41 \\
\hline & Females & 31 & 35 & 32.0 & $32.0-32.8$ & & \\
\hline \multirow[t]{2}{*}{ Mild pain } & Males & 34 & 47 & 38.5 & $35.0-44.0$ & 0.002 & 0.92 \\
\hline & Females & 33 & 39 & 35.0 & $34.0-36.0$ & & \\
\hline \multirow[t]{2}{*}{ Moderate pain } & Males & 37 & 48 & 44.0 & $40.3-47.3$ & 0.007 & 0.99 \\
\hline & Females & 36 & 46 & 38.0 & $38.0-41.8$ & & \\
\hline \multirow[t]{2}{*}{ Mild pain $>$ warmth $^{c}$} & Males & 1.0 & 15.0 & 5.0 & $3.0-10.3$ & 0.037 & 0.84 \\
\hline & Females & 1.0 & 6.0 & 2.5 & $2.0-4.5$ & & \\
\hline \multirow[t]{2}{*}{ Moderate pain $>$ warmth ${ }^{c}$} & Males & 5.0 & 17.0 & 11.5 & $7.0-12.0$ & 0.081 & 0.30 \\
\hline & Females & 3.0 & 13.0 & 6.0 & $5.2-10.0$ & & \\
\hline \multicolumn{8}{|l|}{ Unpleasantness } \\
\hline \multirow[t]{2}{*}{ Warmth } & Males & 0.0 & 8.0 & 0.5 & $0.0-2.7$ & 0.379 & 0.30 \\
\hline & Females & 0.0 & 4.5 & 0.0 & $0.0-2.2$ & & \\
\hline \multirow[t]{2}{*}{ Mild pain } & Males & 0.0 & 16.0 & 3.8 & $0.1-7.3$ & 0.428 & 0.25 \\
\hline & Females & 0.0 & 5.0 & 3.5 & $0.0-5.0$ & & \\
\hline \multirow[t]{2}{*}{ Moderate pain } & Males & 2.5 & 19.0 & 7.0 & $5.0-11.8$ & 0.028 & 0.72 \\
\hline & Females & 0.0 & 9.0 & 5.0 & $3.1-7.8$ & & \\
\hline \multirow[t]{2}{*}{ Mild pain > warmth ${ }^{d}$} & Males & -8.0 & 16.0 & 3.0 & $0.1-4.0$ & 0.431 & 0.76 \\
\hline & Females & 0.0 & 5.0 & 1.5 & $0.0-3.0$ & & \\
\hline \multirow[t]{2}{*}{ Moderate pain $>$ mild pain ${ }^{d}$} & Males & -3.0 & 19.0 & 6.3 & $5.0-9.0$ & 0.051 & 0.78 \\
\hline & Females & 0.0 & 9.0 & 4.3 & $2.7-5.0$ & & \\
\hline
\end{tabular}

Summary of psychophysics of temperature thresholds necessary to produce warmth, mild pain, or moderate pain, and unpleasantness ratings at each condition (age/matched $N=24 ; n=12$ male; $n=12$ female)

${ }^{a} p$ value derived from post hoc Wald $X_{(d f=1)}^{2}$ tests of group differences for each condition

${ }^{\mathrm{b} C o h e n ' s ~} d$ for transformed normal data

'Difference in degrees Celsius between mild pain and moderate pain

${ }^{d}$ Difference between verbal report of mild pain and moderate pain (0-20 unpleasantness scale) 
programmed with each participant's average temperature rated as producing warmth, mild pain, and moderate pain percepts derived during the pain psychophysics testing session. An fMRI block design with six thermal stimulation periods (two at each intensity; duration $16 \mathrm{~s}$ each) followed by baseline $\left(30{ }^{\circ} \mathrm{C}\right)$ periods (duration 24 s) was used (Fig. 2). To avoid order effects, each thermal condition was pseudo-randomly delivered two times over four functional runs. During each functional run, lights remained on and participants were instructed to be as still as possible and to remain awake with eyes open. After each functional run, study personnel verbally communicated with each participant to confirm alertness and comfort with study continuation. Visual and audio contact was maintained during all scanning procedures.

\section{Image processing}

Slice timing correction and motion correction (using standard rigid body registration of intra-scan volumes) were applied to the fMRI data using standard SPM8 techniques. Using the first image volume from each fMRI imaging run, volumes were co-registered to structural T1weighted volumes. Images were spatially smoothed with an 8-mm full-width half-maximum (FWHM) Gaussian kernel. Structural data were registered to Montreal Neuroimaging Institute (MNI) space and the resulting transformation matrix was applied to the fMRI data.

\section{Data analysis}

Whole-brain fMRI activation was modeled as the contrast of temperature stimuli (those temperatures perceived as producing warmth versus mild pain versus

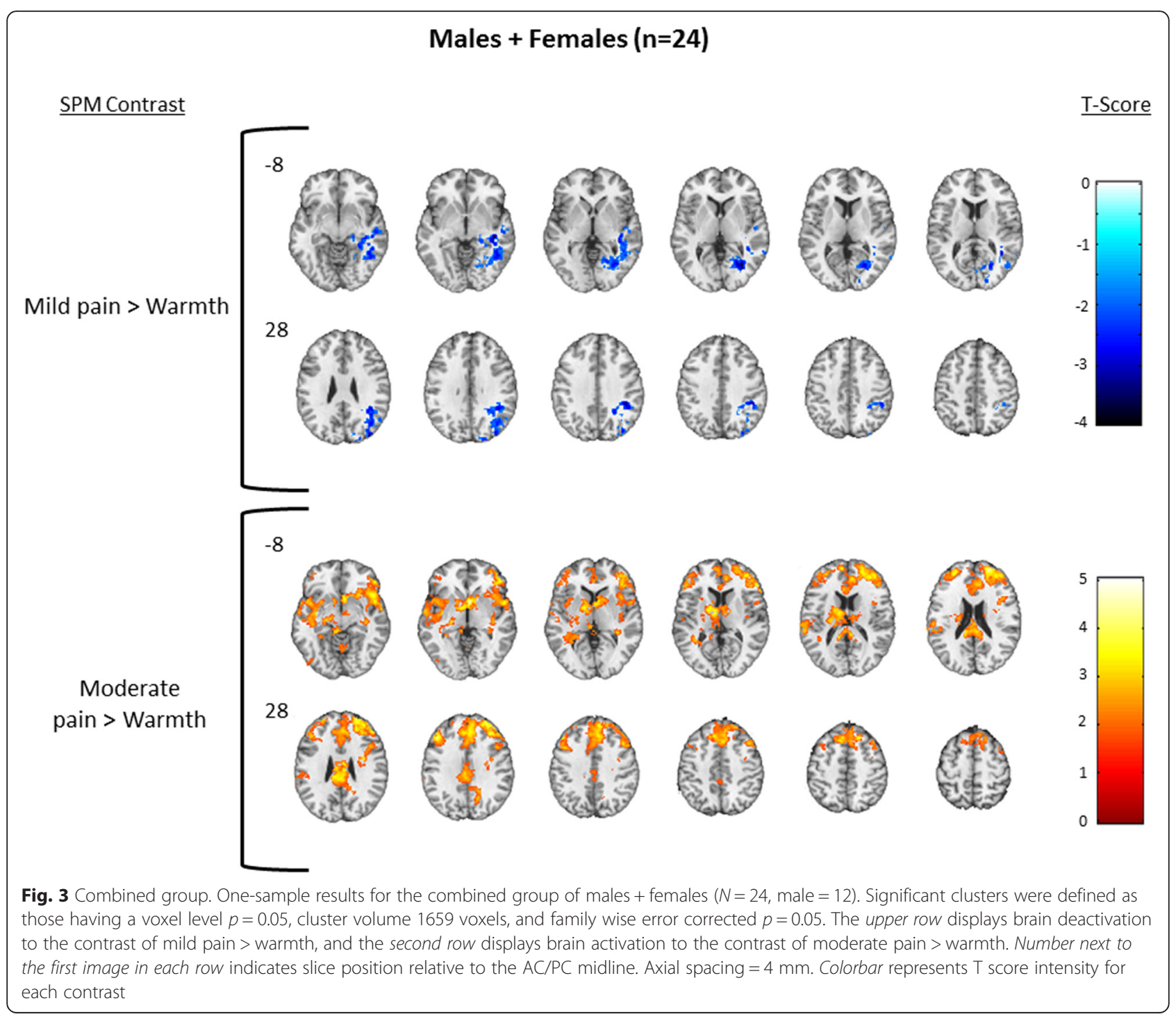


moderate pain against a fixed baseline). We also modeled the period required for the thermal probe to ramp up to target temperature and to ramp down from target temperatures. Because individual temperature threshold precepts were measured, ramp up and ramp down periods and individual temperature percepts were modeled as covariates of no interest in the general linear model (GLM). These resulting subject-specific contrast maps were used in higher-level analyses for between-group comparisons and within-group analysis in SPM8 to compare noxious pain (mild and moderate) versus innocuous warmth. These analyses generated an activation map of $\mathrm{t}$-statistics that were used to identify brain regions indicating statistically significant between-group (male versus female) activation differences. To account for multiple comparisons, statistical thresholds for these higher-level analyses were corrected using the intrinsic smoothness of the data [35] and Monte Carlo simulations in 3dClustSim (http://afni.nimh.nih.gov/pub/dist/doc/program_help/3dClustSim.html) at 10,000 iterations to produce family wise error corrected data $(p \leq 0.05)$ based on whole-brain analysis with a cluster size of 1659 voxels for significance. After generating whole-brain statistically significant clusters, peak MNI coordinates were identified in pain regions of interest (ROIs) within those clusters. Using Marsbar [36], we created 3-mm spheres around select peak coordinates in pain processing regions and extracted the average signal for each ROI activated in males and

Table 3 Females and males whole-brain activation ( $n=24$; males $=12)$

\begin{tabular}{|c|c|c|c|c|c|c|}
\hline \multirow[t]{2}{*}{ SPM contrast } & \multirow{2}{*}{$\begin{array}{l}\text { Cluster region } \\
\text { Subregions (BA) }\end{array}$} & \multirow{2}{*}{$\begin{array}{l}\text { Volume } \\
\left(\mathrm{mm}^{3}\right)\end{array}$} & \multirow[t]{2}{*}{ Peak T } & \multicolumn{3}{|c|}{ MNI coordinates } \\
\hline & & & & $x$ & $y$ & $z$ \\
\hline \multirow[t]{15}{*}{ Mild pain < warmth } & Right cerebrum & & -3.96 & 48 & -54 & -14 \\
\hline & Superior temporal gyrus & 2744 & & 43 & -47 & 17 \\
\hline & Cuneus & 2152 & & 18 & -79 & 25 \\
\hline & Precuneus & 1623 & & 12 & -64 & 26 \\
\hline & Supramarginal gyrus & 1488 & & 42 & -44 & 31 \\
\hline & Middle occipital gyrus & 992 & & 31 & -65 & 1 \\
\hline & Dorsal posterior cingulate gyrus & 840 & & 23 & -64 & 3 \\
\hline & Right hippocampus & 824 & & 20 & -30 & -3 \\
\hline & Fusiform gyrus (37) & 672 & & 47 & -54 & -18 \\
\hline & Superior temporal gyrus (22) & 440 & & 64 & -46 & 3 \\
\hline & Right postcentral gyrus $(1,2,3)$ & 328 & & 46 & -38 & 61 \\
\hline & Cingulate cortex (30) & 296 & & 20 & -67 & 8 \\
\hline & Inferior temporal gyrus (20) & 216 & & 49 & -54 & -15 \\
\hline & Insula (13) & 200 & & 44 & -15 & 3 \\
\hline & Middle temporal gyrus (21) & 176 & & 61 & -18 & -7 \\
\hline \multirow[t]{12}{*}{ Moderate pain > warmth } & Left cerebrum & & 4.03 & -32 & -84 & -30 \\
\hline & Occipital lobe & 2384 & & -35 & -77 & -18 \\
\hline & Cerebellum & 1904 & & -6 & -62 & -34 \\
\hline & Left fusiform gyrus & 936 & & -41 & -74 & -17 \\
\hline & Middle occipital gyrus & 928 & & -42 & -71 & -15 \\
\hline & Middle frontal gyrus & 896 & & -1 & 39 & 31 \\
\hline & Pons & 624 & & 13 & -41 & -38 \\
\hline & Right brainstem & 576 & & 6 & -44 & -45 \\
\hline & Associative visual cortex (19) & 392 & & -35 & -84 & -14 \\
\hline & Left brainstem & 360 & & -18 & -30 & -33 \\
\hline & Cerebellum & 304 & & -11 & -58 & -34 \\
\hline & Lingual gyrus & 136 & & -33 & -84 & -15 \\
\hline
\end{tabular}

One sample combined males + females analysis. Significant clusters were derived using 3dClustSim and the intrinsic smoothness of the data to define corrected whole-brain cluster thresholds as those having a voxel level $p=0.05$, cluster volume 1659 voxels, volume $>120 \mathrm{~mm}^{3}$, and family wise error corrected $p=0.05$. Areas are reported with the parent cluster first defined by Peak T, followed by subregions within each cluster (MNI coordinates of subregions are approximate). Mild pain $<$ warmth $=$ deactivations; moderate pain $>$ warmth $=$ activations

SPM Statistical Parametric Mapping, BA Brodmann area, MNI Montreal Neuroimaging Institute 
females for each contrast/condition to use in analyses of the association of psychophysical reports with brain activation.

Demographic and standardized sample characteristics were non-normally distributed and summarized using median and 25th to 75th inter-quartile ranges (IQR; continuous data) and Ns (percentages; categorical data). Medians and IQR were also used to summarize the psychophysical and ROI percent signal change data. MannWhitney tests were used to test for sex differences in the self-reported temperature and unpleasantness ratings at each of the pain sensory levels, as well as difference in the amount of change in those self-reports between pain levels. Associations of psychophysics (temperature intensity and unpleasantness) changes with respective contrast signal change values in ROIs associated with pain were assessed using linear regression analyses. To match the signal change contrast conditions (e.g. mild versus warm), each analysis controlled for the temperature and unpleasantness ratings in the referent pain condition also (e.g. warm temperature or unpleasantness if the focus in on the mild versus warm signal change condition). Tests of differences between the groups in the strength of those regression coefficients were conducted using the $z$ test for independent correlations. Because this study focuses on a subset of participants in an ongoing larger study and because it is a preliminary investigation of the phenomena, statistical powering for this specific study was not conducted, rather, the primary focus is on the effect sizes observed. Thus, effect indices (e.g., Cohen's $d$ and beta coefficients) are reported with respective statistical $p$ values and if of sufficient magnitude to demonstrate promising potential for future research, may be interpreted even if the respective $p$ value does not meet the statistical significance criteria. Those findings, of course, are interpreted with caution. For these same reasons, we did not use any type of correction to the alpha level used. Unless otherwise noted, $p<0.05$ was used for determining statistical significance.

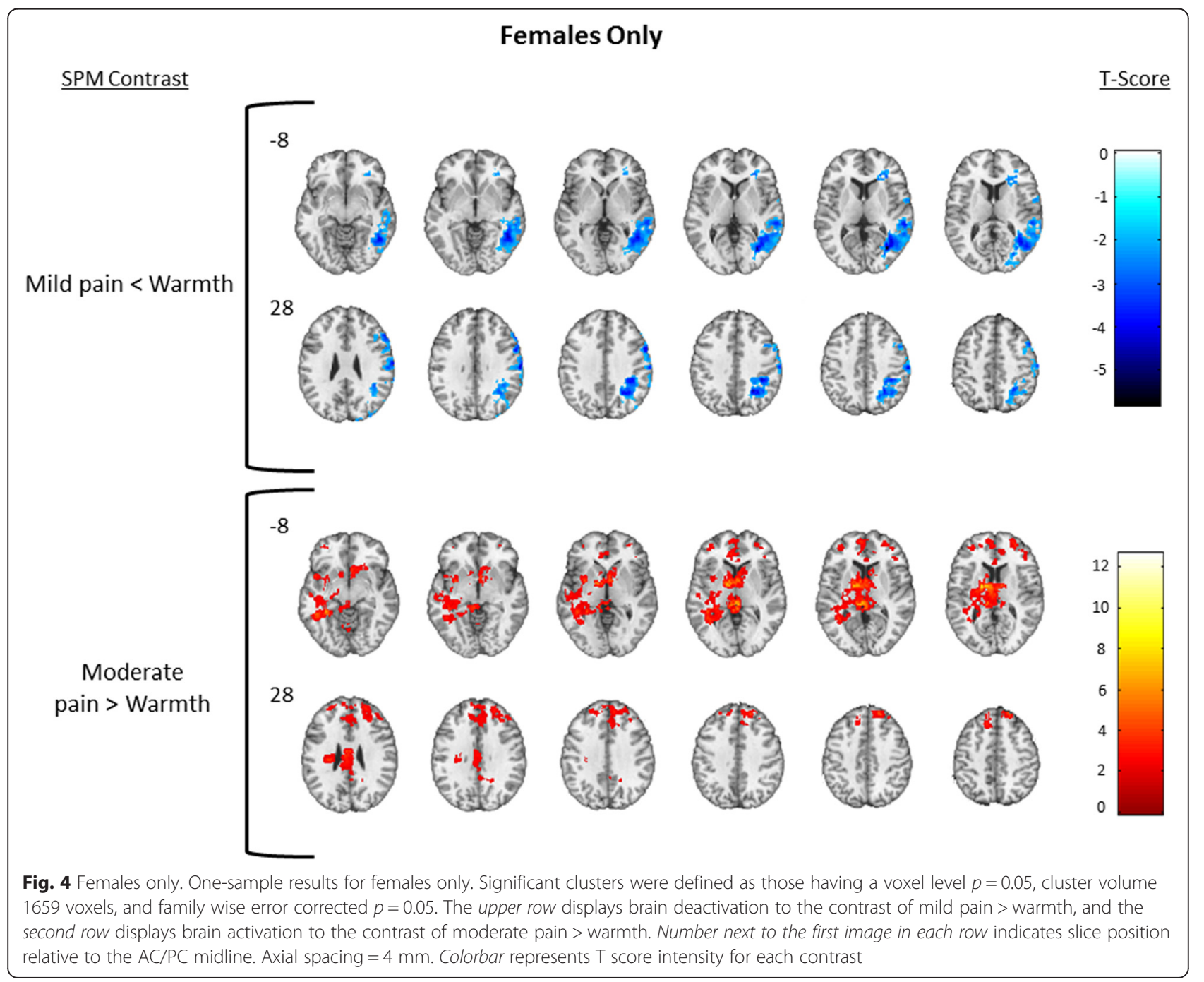




\section{Results}

\section{Demographics}

There were no statistically significant differences between females and males on average or current bodily pain (BPI [28]), depression (GDS [29]), state or trait anxiety (STAI [30]), cognitive status (MMSE [23]), or SES (Hollingshead Four-Factor SES [26]) scores (see Table 1; all $p>0.05$ ).

\section{Psychophysical results \\ Sensory}

Statistically significant sex differences were observed for the stimulus intensity required to evoke mild and moderate pain, with females reporting both mild and moderate pain at lower temperatures than the males (Cohen's $d=0.92$ and 0.99 , respectively, $p<0.01$ ). In contrast, non-painful warmth was perceived at similar temperatures for both sexes (Cohen's $d=0.41, p=0.186$ ). When compared to males, females demonstrated less change in temperature values between their reported warm and mild pain levels (Cohen's $d=0.84, p=0.037$; see Table 2 ).

\section{Affective}

Ratings of unpleasantness were similar for males and females for both the warmth and mild pain conditions; yet, at the moderate pain intensity level, females provided lower ratings of unpleasantness than males (median 5.0 versus 7.00, Cohen's $d=0.72, p=0.028$; see Table 2). This apparent sex difference in the amount of change in reported unpleasantness between mild and moderate pain was confirmed with the statistically significant difference in those values. While not statistically significant, females reported less change in unpleasantness between warm and both mild and moderate pain detection levels than did males with rather large difference effect sizes (Cohen's $d=0.76-0.78$; see Table 2).

\section{fMRI results}

\section{One-sample results}

To describe the overall pattern of activation produced by thermal stimulation, we first created one-sample $T$ test maps showing brain regions activated during each level of thermal stimulation in the combined sample of males and females. For each of the contrasts mild pain > warmth and moderate pain > warmth, results from one-sample $T$ tests for females and males combined $(n=24)$ are shown in Fig. 3 ; detailed cluster information is shown in Table 3 . The combined male + female one-sample contrast of mild $>$ warmth demonstrated deactivation only that was confined to regions associated with core structures in the default mode network (DMN; e.g., cuneus, precuneus, posterior cingulate gyrus (PCG), hippocampus (HIPPO) [37]) and in regions commonly associated with pain (e.g., postcentral gyrus/somatosensory cortex and INS), while the moderate pain > warmth only demonstrated significant activation in regions including cerebellum, fusiform gyrus (FG), and pons. To further describe the within-group patterns of activation, one-sample $T$ test maps are shown for female only $(n=12)$ in Fig. 4 and males only $(n=12)$ in Fig. 5; detailed cluster information is shown in Tables 4 and 5 , respectively.

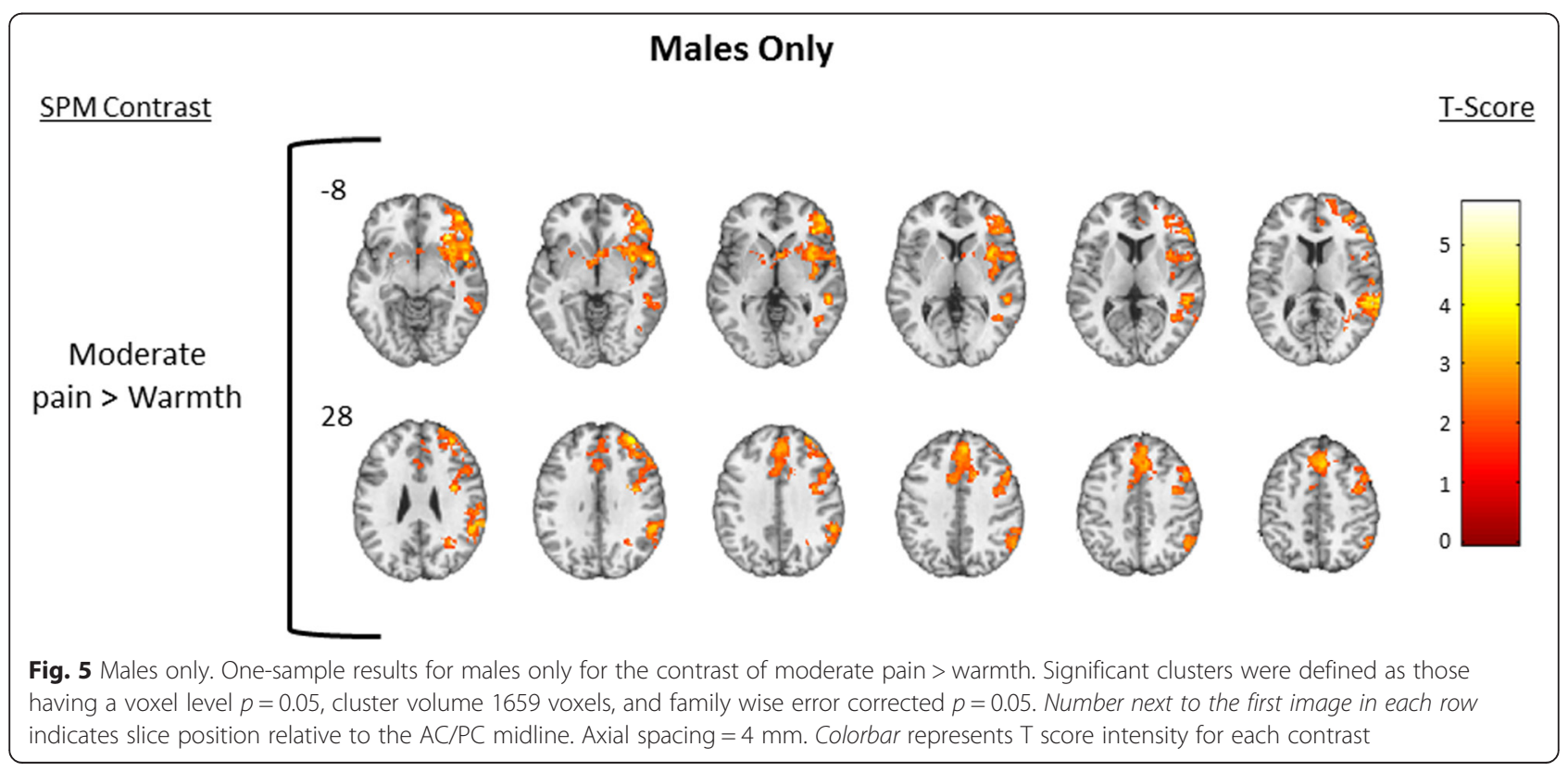


Table 4 Female-only whole-brain activation $(n=12)$

\begin{tabular}{|c|c|c|c|c|c|c|}
\hline \multirow[t]{2}{*}{$\begin{array}{l}\text { SPM } \\
\text { contrast }\end{array}$} & \multirow{2}{*}{$\begin{array}{l}\text { Cluster region } \\
\text { Subregions (BA) }\end{array}$} & \multirow{2}{*}{$\begin{array}{l}\text { Volume } \\
\left(\mathrm{mm}^{3}\right)\end{array}$} & \multirow[t]{2}{*}{ Peak T } & \multicolumn{3}{|c|}{$\begin{array}{l}\text { MNI } \\
\text { coordinates }\end{array}$} \\
\hline & & & & $x$ & $y$ & $z$ \\
\hline \multirow{16}{*}{$\begin{array}{l}\text { Mild Pain < } \\
\text { Warmth }\end{array}$} & Right cerebrum & & -5.76 & 34 & -68 & 6 \\
\hline & Temporal lobe & 30,040 & & 48 & -55 & -13 \\
\hline & Parietal lobe & 17,528 & & 40 & -40 & 39 \\
\hline & $\begin{array}{l}\text { Middle temporal } \\
\text { gyrus (21) }\end{array}$ & 13,032 & & 61 & -31 & 1 \\
\hline & $\begin{array}{l}\text { Superior temporal } \\
\text { gyrus (22) }\end{array}$ & 8800 & & 58 & -40 & 8 \\
\hline & $\begin{array}{l}\text { Right postcentral } \\
\text { gyrus }(1,2,3)\end{array}$ & 4152 & & 62 & -18 & 27 \\
\hline & $\begin{array}{l}\text { Right precentral } \\
\text { gyrus }\end{array}$ & 3088 & & 58 & 5 & 34 \\
\hline & $\begin{array}{l}\text { Right fusiform } \\
\text { gyrus (37) }\end{array}$ & 2576 & & 47 & -52 & -19 \\
\hline & $\begin{array}{l}\text { Secondary } \\
\text { somatosensory } \\
\text { cortex (40) }\end{array}$ & 2120 & & 39 & -55 & 42 \\
\hline & Cuneus & 1936 & & 23 & -88 & 17 \\
\hline & Precuneus & 1880 & & 23 & -60 & 44 \\
\hline & $\begin{array}{l}\text { Premotor } \\
\text { cortex (6) }\end{array}$ & 1456 & & 59 & -6 & 37 \\
\hline & $\begin{array}{l}\text { Somatosensory } \\
\text { association } \\
\text { cortex ( } 7 \text { ) }\end{array}$ & 1344 & & 29 & -53 & 46 \\
\hline & $\begin{array}{l}\text { Dorsolateral prefrontal } \\
\text { cortex (9) }\end{array}$ & 1136 & & 58 & 5 & 34 \\
\hline & $\begin{array}{l}\text { Primary motor } \\
\text { cortex (4) }\end{array}$ & 568 & & 60 & -21 & 44 \\
\hline & Insula & 128 & & 41 & -28 & -3 \\
\hline \multirow{15}{*}{$\begin{array}{l}\text { Moderate } \\
\text { Pain }> \\
\text { Warmth }\end{array}$} & $\begin{array}{l}\text { Cluster 1: left } \\
\text { cerebellum }\end{array}$ & & 4.50 & -30 & -76 & -42 \\
\hline & $\begin{array}{l}\text { Cerebellum } \\
\text { posterior lobe }\end{array}$ & 9984 & & -28 & -55 & -41 \\
\hline & Cerebellar tonsil & 6432 & & -9 & -55 & -42 \\
\hline & $\begin{array}{l}\text { Cerebellum } \\
\text { anterior lobe }\end{array}$ & 4152 & & -27 & -54 & -39 \\
\hline & Right cerebellum & 2008 & & 8 & -51 & -43 \\
\hline & Declive & 1632 & & -28 & -79 & -29 \\
\hline & Culmen & 1296 & & 0 & -54 & -18 \\
\hline & Dentate & 496 & & 12 & -47 & -33 \\
\hline & Pons & 416 & & -2 & -19 & -26 \\
\hline & Right brainstem & 304 & & 6 & -47 & -45 \\
\hline & Left brainstem & 144 & & -2 & -44 & -39 \\
\hline & $\begin{array}{l}\text { Cluster 2: left } \\
\text { cerebrum }\end{array}$ & & 12.65 & -16 & -6 & 14 \\
\hline & Right cerebrum & 12,064 & & 1 & 4 & 1 \\
\hline & Temporal lobe & 10,664 & & -36 & -50 & 5 \\
\hline & Right thalamus & 6720 & & 4 & -3 & 8 \\
\hline
\end{tabular}

Table 4 Female-only whole-brain activation $(n=12)$ (Continued)

\begin{tabular}{|c|c|c|c|c|c|}
\hline Right caudate & 3336 & & 15 & -12 & 21 \\
\hline $\begin{array}{l}\text { Superior temporal } \\
\text { gyrus }\end{array}$ & 3232 & & -48 & -19 & -1 \\
\hline Caudate head & 2160 & & 7 & 10 & 4 \\
\hline Left caudate & 2032 & & -15 & -2 & 15 \\
\hline $\begin{array}{l}\text { Parahippocampal } \\
\text { gyrus }\end{array}$ & 1720 & & -30 & -41 & -10 \\
\hline Left insula & 1712 & & -29 & -24 & 18 \\
\hline Pulvinar & 1392 & & 6 & -26 & 3 \\
\hline Left putamen & 1312 & & -27 & -14 & 10 \\
\hline Left brainstem & 1072 & & -6 & -35 & -7 \\
\hline $\begin{array}{l}\text { Middle temporal } \\
\text { gyrus }\end{array}$ & 896 & & -37 & -49 & 3 \\
\hline $\begin{array}{l}\text { Ventral posterior } \\
\text { cingulate cortex (23) }\end{array}$ & 880 & & -2 & -30 & 27 \\
\hline Insula (13) & 824 & & -42 & 7 & -11 \\
\hline $\begin{array}{l}\text { Right middle } \\
\text { cingulate cortex }\end{array}$ & 752 & & 1 & -22 & 29 \\
\hline $\begin{array}{l}\text { Anterior cingulate } \\
\text { cortex }\end{array}$ & 616 & & 9 & 23 & -8 \\
\hline $\begin{array}{l}\text { Dorsal posterior } \\
\text { cingulate cortex (31) }\end{array}$ & 360 & & 5 & -47 & 31 \\
\hline $\begin{array}{l}\text { Subgenual } \\
\text { cingulate cortex (25) }\end{array}$ & 328 & & 3 & 9 & -16 \\
\hline Cluster 3: frontal lobe & & 4.67 & 20 & 44 & 44 \\
\hline $\begin{array}{l}\text { Superior frontal } \\
\text { gyrus }\end{array}$ & 9072 & & 27 & 47 & 23 \\
\hline Middle frontal gyrus & 5560 & & 27 & 52 & 16 \\
\hline Anterior cingulate & 3184 & & 12 & 42 & 13 \\
\hline $\begin{array}{l}\text { Anterior prefrontal } \\
\text { cortex (10) }\end{array}$ & 3000 & & 26 & 49 & 28 \\
\hline $\begin{array}{l}\text { Dorsolateral } \\
\text { prefrontal cortex (9) }\end{array}$ & 2088 & & 33 & 36 & 31 \\
\hline $\begin{array}{l}\text { Dorsal anterior } \\
\text { cingulate cortex (32) }\end{array}$ & 1536 & & -6 & 35 & 29 \\
\hline $\begin{array}{l}\text { Ventral anterior } \\
\text { cingulate cortex (24) }\end{array}$ & 448 & & 6 & 29 & 17 \\
\hline
\end{tabular}

One-sample female-only analysis. Significant clusters were derived using $3 \mathrm{dClustSim}$ and the intrinsic smoothness of the data to define corrected whole-brain cluster thresholds as those having a voxel level $p=0.05$, cluster volume 1659 voxels, volume $>120 \mathrm{~mm}^{3}$, and family wise error corrected $p=0.05$. Areas are reported with the parent cluster first defined by Peak $T$, followed by subregions within each cluster (MNI coordinates of subregions are approximate). Mild pain $<$ warmth $=$ deactivations;

moderate pain $>$ armth $=$ activations

SPM Statistical Parametric Mapping, BA Brodmann area, MNI Montreal Neuroimaging Institute

\section{Between-group comparison of males versus females (males $>$ females, females $>$ males)}

In the between-group contrasts of females $>$ males, females demonstrated less deactivation in several bilateral brain regions in the mild pain $>$ warmth contrast including the dIPFC, rostral ACC (rACC), and dorsal ACC (dACC) 
Table 5 Male-only whole-brain activation $(n=12)$

\begin{tabular}{|c|c|c|c|c|c|c|}
\hline \multirow[t]{2}{*}{ SPM contrast } & \multirow{2}{*}{$\begin{array}{l}\text { Cluster region } \\
\text { subregions (BA) }\end{array}$} & \multirow{2}{*}{$\begin{array}{l}\text { Volume } \\
\left(\mathrm{mm}^{3}\right)\end{array}$} & \multirow{2}{*}{$\begin{array}{l}\text { Peak } \\
T\end{array}$} & \multicolumn{3}{|c|}{ MNI coordinates } \\
\hline & & & & $x$ & $y$ & $z$ \\
\hline \multirow[t]{30}{*}{ Moderate pain $>$ warmth } & Cluster 1: right cerebrum & & 5.50 & 40 & -2 & -22 \\
\hline & Middle frontal gyrus & 13,424 & & 6 & 40 & 39 \\
\hline & Inferior frontal gyrus & 13,152 & & 47 & 38 & -9 \\
\hline & Superior frontal gyrus & 9408 & & 1 & 4 & 63 \\
\hline & Right insula (13) & 6824 & & 35 & 8 & -12 \\
\hline & Superior temporal gyrus (22) & 4224 & & 59 & -36 & 21 \\
\hline & Right premotor cortex (6) & 4080 & & 16 & 16 & 62 \\
\hline & Right supplemental motor area (6) & 3440 & & 15 & 22 & 62 \\
\hline & Inferior frontal gyrus (47) & 2744 & & 50 & 34 & -10 \\
\hline & Dorsolateral prefrontal cortex (9) & 2576 & & 45 & 29 & 33 \\
\hline & Dorsal anterior cingulate cortex (32) & 2392 & & 11 & 38 & 21 \\
\hline & Precentral gyrus & 1936 & & 55 & 5 & 8 \\
\hline & Anterior prefrontal cortex (10) & 1632 & & 24 & 55 & 27 \\
\hline & Right putamen & 1568 & & 24 & 14 & -5 \\
\hline & Temporopolar area (38) & 1040 & & 41 & 23 & -25 \\
\hline & Caudate head & 560 & & 5 & 9 & -3 \\
\hline & Orbitofrontal area (11) & 536 & & 27 & 25 & -15 \\
\hline & Putamen & 536 & & -23 & 12 & -3 \\
\hline & Middle temporal gyrus (21) & 184 & & 59 & -22 & -14 \\
\hline & Subgenual cingulate cortex (25) & 152 & & 5 & 12 & -8 \\
\hline & Parahippocampal gyrus (34) & 128 & & 34 & -4 & -23 \\
\hline & Cluster 2: right cerebrum & & 5.70 & 60 & -18 & 20 \\
\hline & Superior temporal Gyrus (22) & 6120 & & 58 & 1 & -4 \\
\hline & Middle temporal gyrus (21) & 3376 & & 56 & 8 & -18 \\
\hline & Supramarginal gyrus (40) & 3256 & & 58 & -41 & 32 \\
\hline & Right postcentral gyrus & 2032 & & 58 & -20 & 20 \\
\hline & Insula (13) & 536 & & 41 & -7 & 2 \\
\hline & Angular gyrus (39) & 368 & & 39 & -56 & 22 \\
\hline & Secondary somatosensory cortex (42) & 280 & & 62 & -35 & 20 \\
\hline & Right fusiform gyrus & 160 & & 47 & -28 & -19 \\
\hline
\end{tabular}

One-sample male only analysis. Significant clusters were derived using 3dClustSim and the intrinsic smoothness of the data to define corrected whole-brain cluster thresholds as those having a voxel level $p=0.05$, cluster volume 1659 voxels, volume $>120 \mathrm{~mm}^{3}$, and family wise error corrected $p=0.05$. Areas are reported with the parent cluster first defined by Peak $\mathrm{T}$, followed by subregions within each cluster (MNI coordinates of subregions are approximate)

SPM Statistical Parametric Mapping, BA Brodmann area, MNI Montreal Neuroimaging Institute

(Fig. 6; Table 6), while in the between-group contrast of males $>$ females, males demonstrated greater activation in several ipsilateral brain regions in the moderate pain > warmth contrast including the pINS, SI, and SII (Fig. 7; Table 6). See Table 7 for MNI coordinates corresponding to pain regions labeled in Figs. 6 and 7. To aid in the interpretation of the findings in Figs. 3, 4, 5, 6, and 7, the pattern of blood oxygenation level dependent (BOLD) signal change for each condition relative to baseline is shown in Additional file 1: Figure S1 and Additional file 2: Figure S2.

\section{Associations between activation and psychophysical results}

To explore and describe the perceptual importance of significant sex differences in brain activations, we examined the associations of the BOLD signal change values in each of the ROIs above showing significant sex differences with psychophysical self-reports. Summaries of these associations for all 24 participants and for each sex ( $n=12$ in each group) are described in Table 7. Signal change values for each ROI are presented in Figs. 8 and 9. 


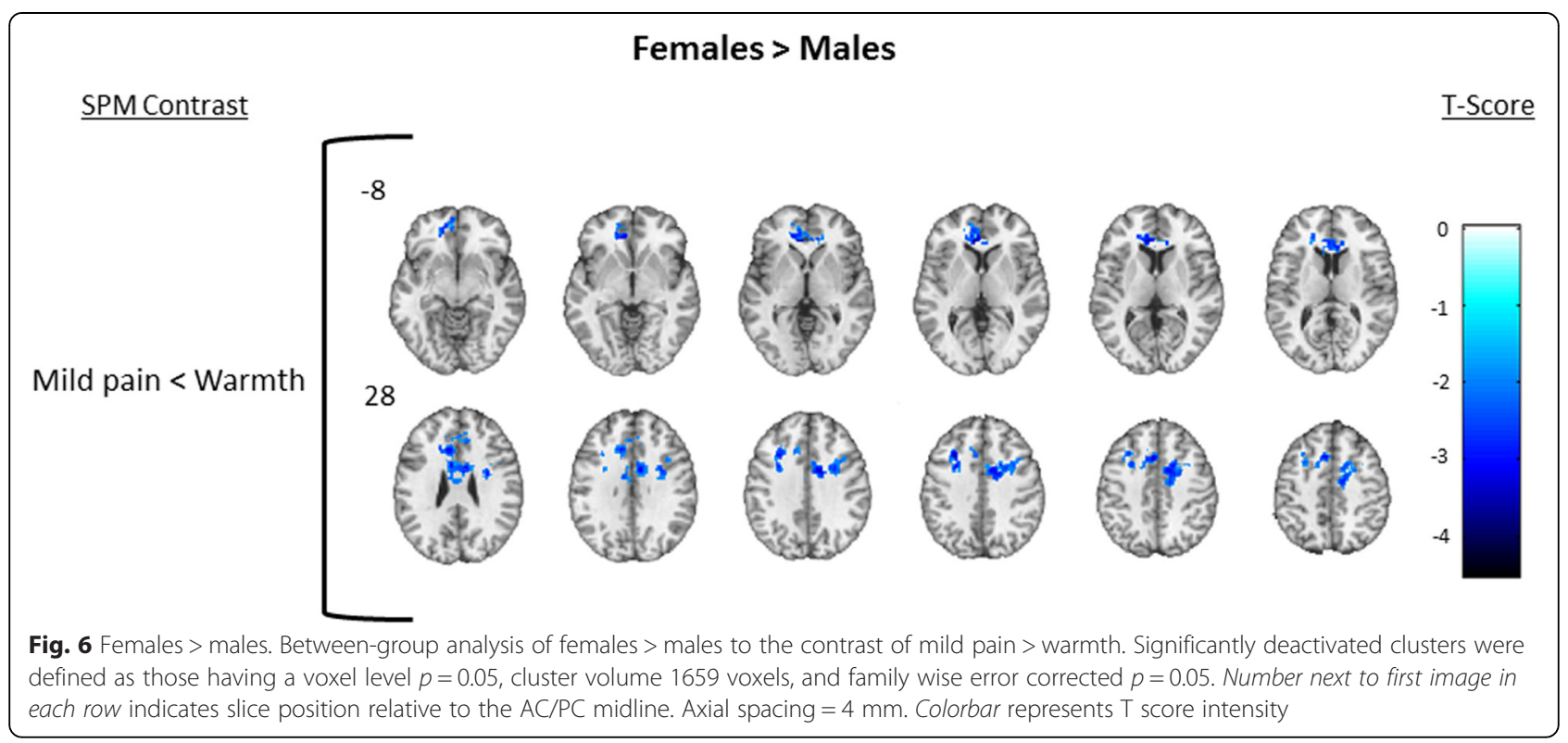

\section{Mild pain > warmth}

A statistically significant and contrasting pattern of effect sizes by sex for the associations of deactivation levels with perceived unpleasantness was observed for the left (contralateral) rACC region (males: beta $=0.34$ or positive relationship; females: beta $=-0.56$ or inverse relationship; two-tailed $z=2.09, p=0.037$ ). Higher levels of deactivation in left rACC were associated with less change in unpleasantness between warmth to mild pain in females but not so for males. Within the left rACC, higher levels of deactivation tended to be associated with greater increases in unpleasantness from warmth to mild pain for males (Fig. 10). No other statistically significant associations were observed.

\section{Moderate pain > warmth}

Greater BOLD signal changes in right (ipsilateral) SII were associated with greater increases in self-reported unpleasantness ratings between the moderate pain and warmth conditions across both females and males (beta $=0.43, p=0.043$; Fig. 11). No other associations or tests of sex differences in regions activated during the moderate $>$ warmth condition were statistically significant.

\section{Discussion}

To our knowledge, this is the first study to report sex differences in pain perception and brain response to experimental thermal pain in older adults. Our first hypothesis (psychophysical), that when compared to older males, older females would report "mild" and "moderate" pain at lower stimulus intensities (i.e., be more pain sensitive) and would report greater perceived unpleasantness, was partially supported. While older females were more sensitive to pain (i.e., they required lower stimulus temperatures to detect mild and moderate pain intensity), they did not report greater perceived pain unpleasantness. Our second hypothesis (neurophysiological) that, when compared to older males, older females would exhibit greater brain activations in the sensory/discriminative, affective/motivational, and cognitive/evaluative pain networks, was also partially supported. Interestingly, older females demonstrated less deactivation to mild pain in cognitive/evaluative and affective/motivational pain networks. Conversely, while both groups demonstrated only activations to moderate pain, males demonstrated greater activation to moderate pain in the sensory/discriminative pain network. Our overall finding of greater deactivation to mild pain and greater activation to moderate pain are supported by a study in which the relationship and pattern of activations and deactivations to "low" and "high" pain were explored [38]. Kong and colleagues found that participants exhibited greater deactivations in response to "low" pain but exhibited greater activations to "high" pain. These researchers concluded that each of these patterns of signal change (deactivation and activation) contribute to different aspects of the pain experience [35]. For example, varying brain signal changes with activations and deactivations may be associated with an organisms' attempt to evaluate the threat occurring with intense pain or alternatively signal changes could 
Table 6 Between-group whole-brain activation $(n=24$; males $=12)$

\begin{tabular}{|c|c|c|c|c|c|c|}
\hline \multirow[t]{2}{*}{ SPM contrast } & \multirow{2}{*}{$\begin{array}{l}\text { Cluster region } \\
\text { Subregions (BA) }\end{array}$} & \multirow{2}{*}{$\begin{array}{l}\text { Volume } \\
\left(\mathrm{mm}^{3}\right)\end{array}$} & \multirow[t]{2}{*}{ Peak T } & \multicolumn{3}{|c|}{ MNI coordinates } \\
\hline & & & & $x$ & $y$ & $z$ \\
\hline \multicolumn{7}{|c|}{ Mild pain > warmth (deactivation) } \\
\hline \multirow[t]{11}{*}{ Females $>$ males } & Left cerebrum & & 4.51 & -6 & 34 & 4 \\
\hline & Limbic lobe & 14,608 & & -8 & 21 & 25 \\
\hline & Rostral anterior cingulate cortex (24) & 2312 & & -3 & 36 & 5 \\
\hline & Middle frontal gyrus & 2280 & & -25 & 12 & 52 \\
\hline & Dorsal anterior cingulate cortex (32) & 2192 & & -7 & 41 & 3 \\
\hline & Superior frontal gyrus & 1432 & & -11 & 11 & 64 \\
\hline & Left supplemental motor area (6) & 912 & & -13 & 12 & 64 \\
\hline & Prefrontal cortex (8) & 320 & & -28 & 17 & 42 \\
\hline & Anterior prefrontal cortex (10) & 288 & & -7 & 49 & 3 \\
\hline & Dorsolateral prefrontal cortex (9) & 256 & & 40 & 15 & 38 \\
\hline & Anterior cingulate cortex (33) & 120 & & -5 & 19 & 25 \\
\hline \multicolumn{7}{|c|}{ Moderate pain > warmth (activation) } \\
\hline \multirow[t]{10}{*}{ Males $>$ females } & Right cerebrum & & 3.51 & 32 & -58 & 28 \\
\hline & Superior temporal gyrus (22) & 3304 & & 55 & -37 & 9 \\
\hline & Middle temporal gyrus & 2472 & & 43 & -63 & 5 \\
\hline & Postcentral gyrus $(1,2,3)$ & 712 & & 59 & -19 & 23 \\
\hline & Insula (13) & 488 & & 44 & -41 & 19 \\
\hline & Precuneus & 464 & & 29 & -64 & 36 \\
\hline & Angular gyrus (39) & 352 & & 35 & -63 & 35 \\
\hline & Secondary somatosensory cortex (40) & 304 & & 59 & -36 & 22 \\
\hline & Fusiform gyrus (37) & 200 & & 48 & -41 & -18 \\
\hline & Supramarginal gyrus & 128 & & 58 & -35 & 24 \\
\hline
\end{tabular}

Between-group analyses. Significant clusters were derived using 3dClustSim and the intrinsic smoothness of the data to define corrected whole-brain cluster thresholds as those having a voxel level $p=0.05$, cluster volume 1659 voxels, volume $>120 \mathrm{~mm}^{3}$, and family wise error corrected (FWE) $p=0.05$. Areas are reported with the parent cluster first defined by Peak T, followed by subregions within each cluster (MNI coordinates of subregions are approximate). Mild pain > warmth, females $>$ males $=$ deactivation (findings result from females being less deactivated than males). Moderate pain $>$ warmth, males $>$ females $=$ activations SPM Statistical Parametric Mapping, BA Brodmann area, MNI Montreal Neuroimaging Institute

be related to the cognitive load occurring with pain [35]. It is plausible that brain deactivations could be related to pro-nociception or activation of anti-nociceptive mechanisms. A seminal study examining the DMN in response to block stimulus events (visual and auditory) found that spontaneous activity in DMN regions occurred during both task and rest and that greater DMN activity during stimulus was associated with greater activation in sensory regions [39]. While many pain studies use paradigms to help ensure that subjects attend to pain [40], studies of passive pain tasks may help uncover the role of the DMN during the experience of mild pain compared to more noxious levels of pain. The clinical importance of attending to mild pain cannot be underestimated. Persistent mild pain may be a first sign of an impending clinical problem requiring medical attention.

With regard to sex-effects on the detection of thermal pain stimuli, our results are in partial agreement with psychophysical studies in younger adults showing that, when compared to younger males, younger females demonstrate significantly lower pain thresholds (increased sensitivity) to both mild and moderate pain (reviewed in [6]). The differences in sensory sensitivity to thermal pain stimuli (i.e., perceptual thresholds) in our sample of older males and females were similar to those previously reported in younger adults. However, in contrast to findings from studies of younger adults (where females generally show greater pain-associated unpleasantness than males; reviewed in [6]), we did not find significant sex differences in pain-related affective responses (measured as stimulus unpleasantness) between males and females, that is, we did not find evidence for increased affective responses to thermal pain in older females (relative to older males) and in fact we found that older females found pain to be less unpleasant. 


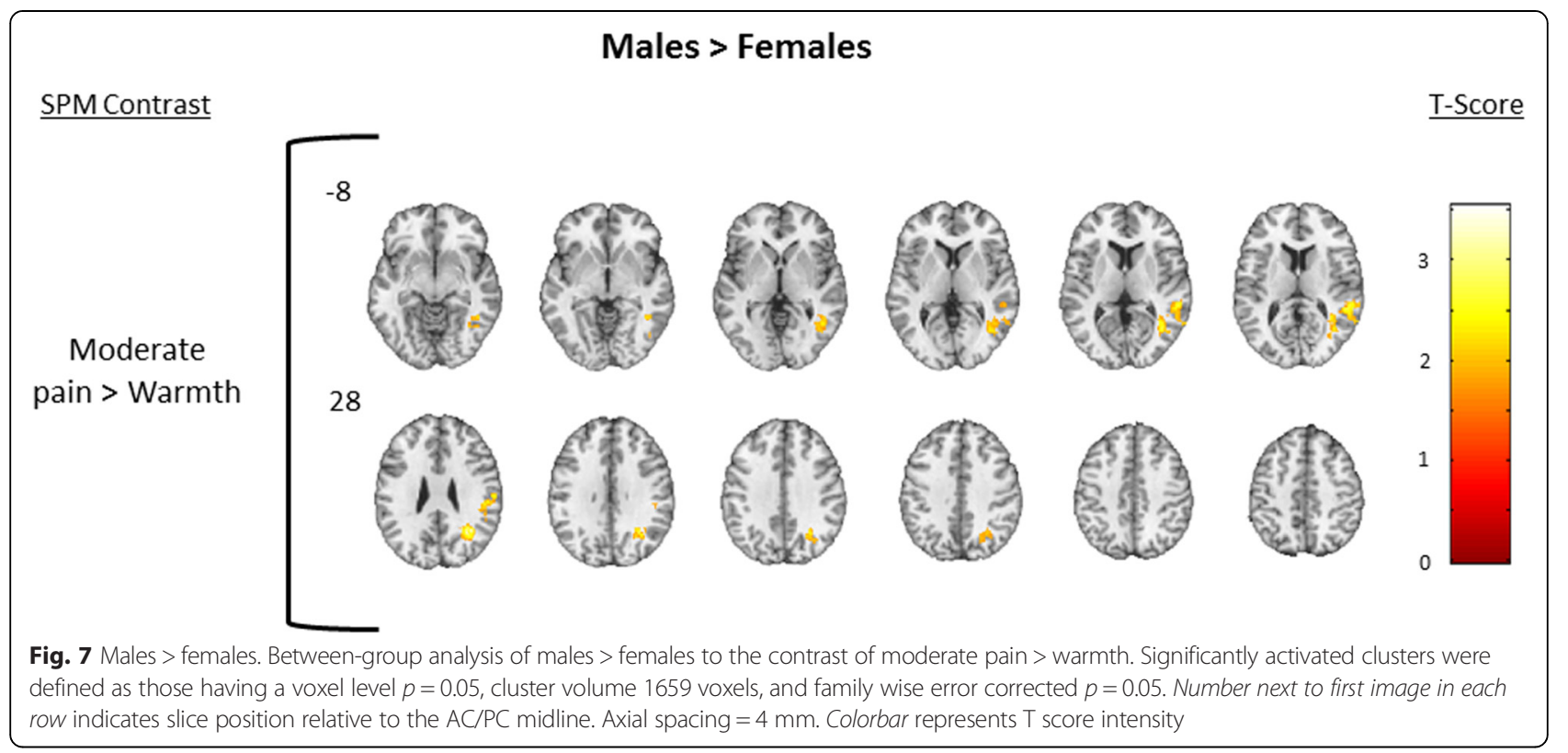

In this sample of older adults, we did find similar sexassociated differences in brain-activation patterns demonstrated in younger individuals. When compared to older males, older females demonstrated greater activation in PFC [20, 21] and ACC [41]. Conversely, and similar to younger individuals, when compared to older females, older males demonstrated increased activation in the SI and SII cortices [41]. Despite these similarities, sex differences in the response to thermal pain in older adults were noted. Older females exhibited lower pain detection

Table 7 Correlations of psychophysical reports with activation in common regions located in sensory and affective pain networks (total: $N=24$, male: $n=12$, female: $n=12$ )

\begin{tabular}{|c|c|c|c|c|c|c|c|c|c|c|}
\hline \multirow[t]{2}{*}{ Region } & \multirow{2}{*}{$\begin{array}{l}\text { MNI coordinate } \\
x, y, z\end{array}$} & \multirow[t]{2}{*}{ T statistic } & \multicolumn{2}{|c|}{ Overall associations } & \multicolumn{3}{|c|}{ Temperature } & \multicolumn{3}{|c|}{ Affect (unpleasantness) } \\
\hline & & & $\overline{T e m p}$ & Affect & Male & Female & $p$ value $^{a}$ & Male & Female & $\overline{p \text { value }}{ }^{a}$ \\
\hline \multirow{2}{*}{\multicolumn{3}{|c|}{ Mild pain < warmth }} & $r_{\mathrm{s}}$ & $r_{\mathrm{s}}$ & $r_{s}$ & $r_{\mathrm{s}}$ & & $r_{\mathrm{s}}$ & $r_{\mathrm{s}}$ & \\
\hline & & & ( $p$ value) & ( $p$ value) & ( $p$ value) & ( $p$ value) & & ( $p$ value) & ( $p$ value) & \\
\hline \multirow[t]{2}{*}{ (L) dIPFC } & $-4+32+34$ & 1.77 & -0.05 & 0.14 & 0.10 & -0.26 & 0.435 & 0.11 & -0.06 & 0.719 \\
\hline & & & $(0.833)$ & $(0.515)$ & $(0.771)$ & $(0.448)$ & & $(0.754)$ & $(0.868)$ & \\
\hline \multirow[t]{2}{*}{ (L) dACC } & $-6+44+1$ & 2.59 & -0.24 & 0.05 & -0.05 & -0.43 & 0.384 & 0.11 & -0.29 & 0.384 \\
\hline & & & $(0.279)$ & $(0.817)$ & $(0.890)$ & $(0.182)$ & & $(0.759)$ & $(0.386)$ & \\
\hline \multirow[t]{2}{*}{ (L) SMA } & $-12+14+66$ & 2.77 & -0.24 & -0.12 & 0.07 & 0.13 & 0.897 & 0.22 & -0.44 & 0.139 \\
\hline & & & $(0.271)$ & $(0.603)$ & $(0.837)$ & $(0.723)$ & & $(0.523)$ & $(0.172)$ & \\
\hline \multirow[t]{2}{*}{ (L) rACC } & $-12+33+24$ & 2.62 & -0.32 & 0.01 & -0.41 & -0.01 & 0.368 & 0.34 & -0.56 & 0.037 \\
\hline & & & $(0.140)$ & $(0.996)$ & $(0.249)$ & $(0.985)$ & & $(0.307)$ & $(0.080)$ & \\
\hline \multicolumn{11}{|c|}{ Moderate $>$ warmth } \\
\hline \multirow[t]{2}{*}{ (R) pINS } & $+51-35+17$ & 2.00 & 0.02 & 0.26 & 0.06 & -0.20 & 0.576 & 0.17 & 0.20 & 0.944 \\
\hline & & & $(0.936)$ & $(0.230)$ & $(0.865)$ & $(0.549)$ & & $(0.621)$ & $(0.556)$ & \\
\hline \multirow[t]{2}{*}{ (R) $\mathrm{SI}$} & $+60-21+28$ & 2.28 & 0.01 & 0.37 & 0.01 & -0.37 & 0.395 & 0.20 & 0.04 & 0.726 \\
\hline & & & $(0.995)$ & $(0.085)$ & $(1.000)$ & $(0.256)$ & & $(0.591)$ & $(0.916)$ & \\
\hline \multirow[t]{2}{*}{ (R) $\mathrm{SII}$} & $+60-34+21$ & 1.99 & 0.07 & 0.43 & 0.28 & -0.27 & 0.230 & 0.51 & 0.37 & 0.711 \\
\hline & & & $(0.765)$ & $(0.043)$ & $(0.423)$ & $(0.419)$ & & $(0.140)$ & $(0.262)$ & \\
\hline
\end{tabular}

Values in each cell are beta and ( $p$ value). Entries in italics indicate either statistically statistic or meaningful effect sizes and respective differences $M N I$ Montreal Neurological Institute, $L$ left, $R$ right, dIPFC dorsolateral prefrontal cortex, $d A C C$ dorsal anterior cingulate cortex, SMA somatomotor area, rACC rostral anterior cingulate cortex, pINS posterior insula, SI primary somatosensory cortex, SII secondary somatosensory cortex ${ }^{a} z$ test of independent correlations 


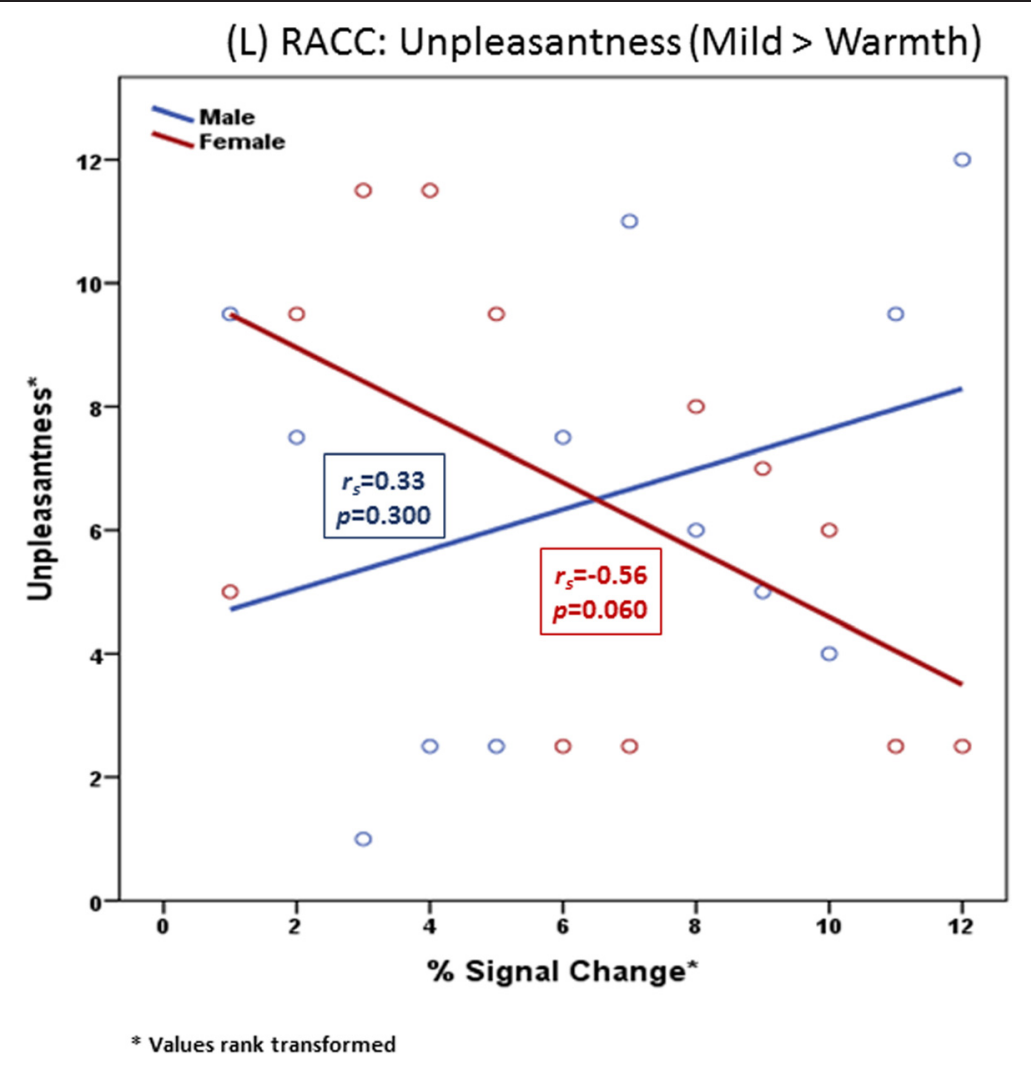

Fig. 8 Rostral anterior cingulate cortex. Sex differences in the association between unpleasantness reported and percent signal change values in the rostral anterior cingulate cortex ( $\mathrm{rACC}$ ) for the condition of mild pain $>$ warmth

temperatures than men (increased pain sensitivity) for both mild and moderate pain, suggesting a greater ability to detect and identify painful stimuli than their male counterparts. However, in general, this increased sensitivity to pain was not reflected in greater activation in the sensory/discriminative pathway but rather via less deactivation in key regions of the DMN (cuneus, precuneus, PCC, HIPPO), somatomotor area (SMA), and in components of both the affective/motivational (rACC, dACC) and cognitive/evaluative networks (dlPFC). While not generally regarded as part of the "pain matrix," the SMA demonstrates functional connectivity with several regions implicated in sensory (e.g., pINS, SI, SII) and affective (e.g., ACC) pain processing (reviewed in [42]).

Though the precise network of pain processing has yet to be determined, the pattern of less deactivation to mild pain and increased sensitivity to overall pain observed in females in the current study could possibly be attributed to decreased efficiency of endogenous opioid systems in aging [43]. Animal studies demonstrate age-associated declines in endogenous opioid system function [44, 45], and these findings appear to extend into humans. Using psychophysics, Washington and colleagues showed that when compared to younger people and in response to similar pain, older people demonstrated a significantly lower endogenous analgesic response concluding that age-associated declines in endogenous opioid systems place older adults at risk for reduced ability to cope with pain [46]. A recent positron emission tomography (PET) found that both gender and age have an effect in central mu-opioid receptor binding. $\mathrm{Mu}$-opioid receptor binding was found to increase with age in neocortical areas and the putamen. Interestingly, when compared to males, pre-menopausal females demonstrated greater central mu-opioid receptor binding in multiple cortical and subcortical regions. However, in post-menopausal females, such as those in the current study, mu-opioid receptor binding decreased to levels below those of men [47]. Considerable evidence supports the role of central muopioid receptor activity in endogenous pain control, and several PET studies have shown mu-opioid receptor activation during acute pain in regions demonstrating deactivation in females in the current study (e.g., ACC and PFC [48-50]). Furthermore, pain-induced activation of the mu-opioid receptor (via endogenous opioid system) was found to negatively correlate with both sensory and affective ratings of pain $[50,51]$. In the current study, sex differences in the association between BOLD signal change and affective pain reports were noted in the left (contralateral) rACC with older males demonstrating 


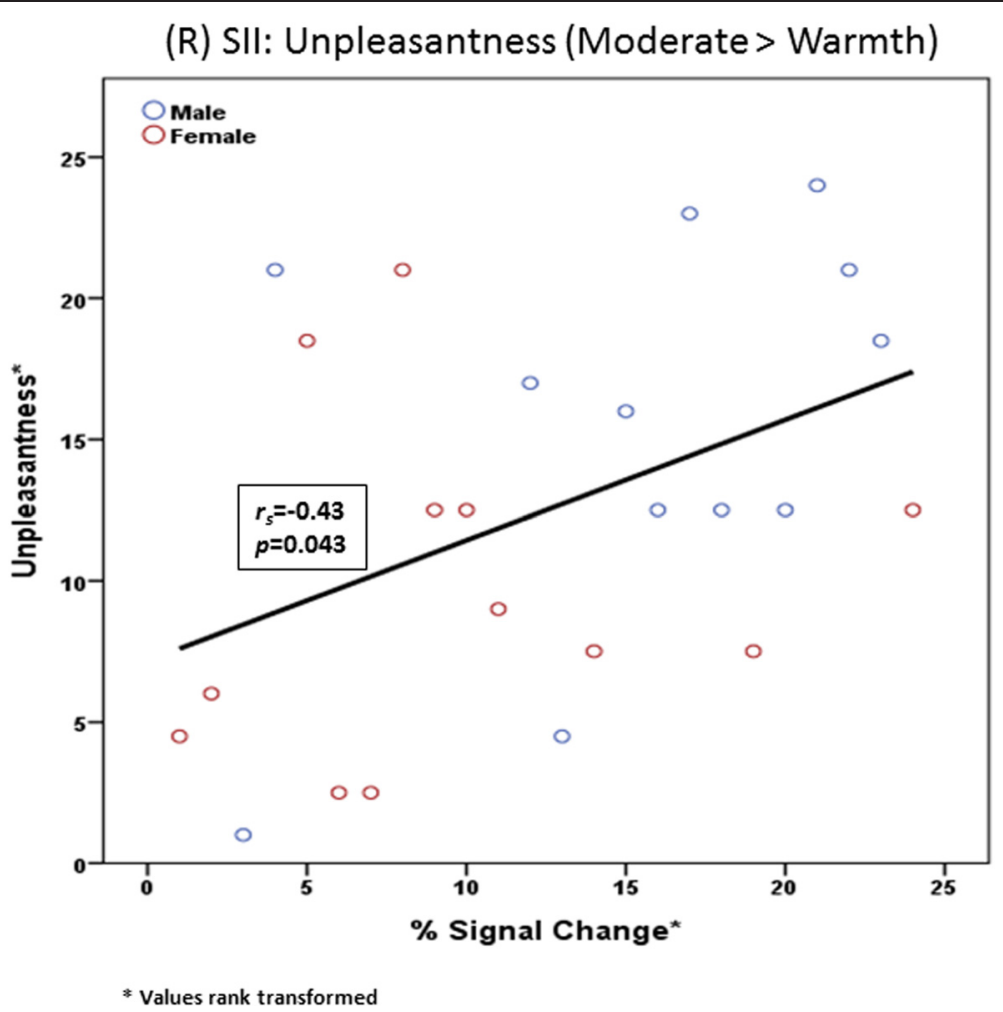

Fig. 9 Secondary somatosensory cortex. Overall group association between unpleasantness reported and percent signal change values in the contralateral secondary somatosensory (SII) cortex for the condition of moderate pain $>$ warmth

positive associations between BOLD signal change and reports of unpleasantness, while older females demonstrated negative associations between BOLD signal change and reports of unpleasantness. Interestingly, we found that among the entire sample of older adults, reported unpleasantness associated with moderate pain was associated with brain signal change in right (ipsilateral) SII. Though the ACC is well known to encode pain affect [52, 53], findings from the current study elevate both the rACC and SII as regions responsible for processing pain affect in older adults.

Contrary to our hypotheses, males exhibited greater activation to moderate pain in lateral (sensory/discriminatory) pain pathway regions than did females (e.g., pINS, SI, and SII). The pINS, SI, and SII collectively function to encode pain intensity and sustained attention to pain [16, 54]. Greater activation in the lateral pain system might be due in part to the greater stimulus intensities (higher temperatures) identified by males as reflecting "mild" and "moderate" pain. Decreased quantity and quality of peripheral a-delta nociceptive fibers have been suggested as a contributory factor leading to increased sensory thresholds in aging [55], and these sex differences in temperature detection thresholds could be the result of greater reductions in epidermal sensory fibers in older males when compared to older females [56].
Although speculative, such differences might result in males requiring greater thermal stimulus intensities to detect pain and consequently exhibit greater brain activation in sensory pain regions.

\section{Limitations}

Because of the small sample size, the interpretation of significant sub-activations in each cluster is assumed based on cluster reports produced via our imaging analyses. As noted by Woo and colleagues [35], the precise location of regions identified in a large activation cluster is difficult to ascertain. Based on further recommendations from Woo and colleagues [35], we report the peak $\mathrm{T}$ and MNI coordinates of the largest regions within each parent cluster followed by the approximate subcluster peak activations. We determined subcluster peak activations by examining for the activation of maximum activation within each subcluster. Since the larger study from which this sub-sample was drawn included people with dementia, our design and methods for examining psychophysics and brain activation were influenced by the protection of cognitively impaired human subjects. Due to this focus on protection, we used a somewhat non-conventional approach to psychophysics in that we used individual percepts in our model and did not measure severe pain or pain tolerance. Thus, careful attention should be made 


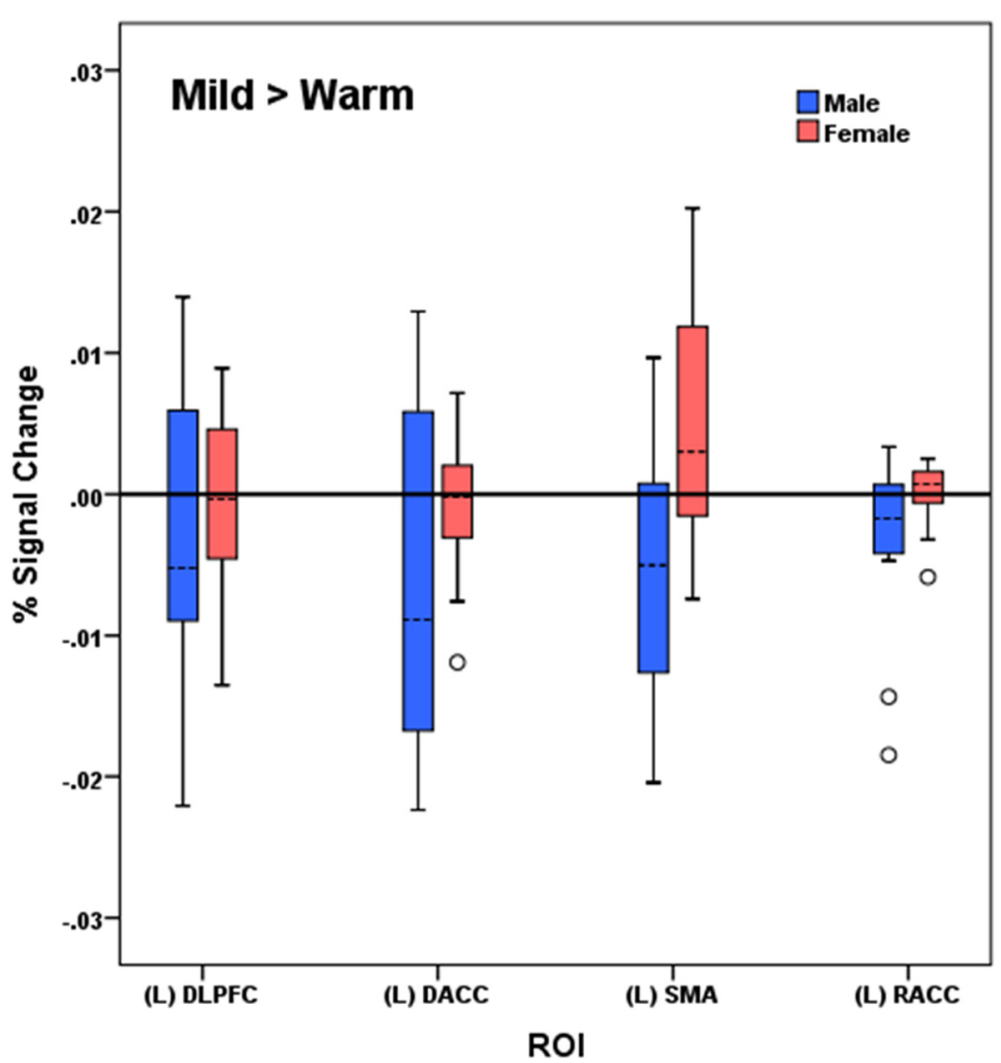

Fig. 10 Mild > warm percent signal change values by sex. Between-group percent signal change values by sex for pain regions of interest in the mild $>$ warm contrast condition. $L=$ left, DLPFC=dorsolateral prefrontal cortex, SMA=somatomotor area, $R A C C=$ rostral anterior cingulate cortex

when comparing the current study findings with other studies. Nonetheless, findings from this study add to the very limited body of psychophysical and neurophysiological research on pain in older adults.

\section{Conclusions}

In summary, the current study found that elevated sensory pain detection levels observed in younger females extends into older females. However, past findings in younger populations that females rate comparable painful stimulus intensities as more unpleasant than do males did not extend into the older population. Interestingly, both males and females demonstrated deactivation in response to mild pain with females demonstrating significantly less deactivation in key regions typically associated with the DMN and pain affect. The DMN is generally posited to engage neural systems that are involved in the monitoring of the "external environment" (e.g., what external threats exist) or invoking an "internal awareness" (e.g., "what is happening to me?"; reviewed in [37]). Each of these suppositions could have clear indications for individuals experiencing pain. It is important to note that the mild and moderate intensity measures used in the current study would not necessarily evoke a lifethreatening feeling.

Current findings further advance the DMN as a system that may mitigate the pain experience and the INS and SII as key regions potentially involved in both sensory and affective pain processing in older adults [43]. Moreover, when compared to males, post-menopausal older females may have altered endogenous opioid systems, which place them at an increased risk of chronic pain and pain-related disability (e.g., avoidance, functional decline). Indeed, reduced baseline pain sensitivity coupled with altered endogenous analgesic systems seems to place individuals at risk for the development of chronic pain (reviewed in [57]). Future directions are to explore the functional connectivity between the DMN, periaqueductal gray (PAG), aINS, and pINS and key brain structures involved with cognitive, evaluative, and modulatory pain processing in older adults. Additionally, studies examining the role of activations and deactivations to thermal pain responses across a wide range of ages may further assist in the interpretation of age- and sexassociated differences in pain processing. 


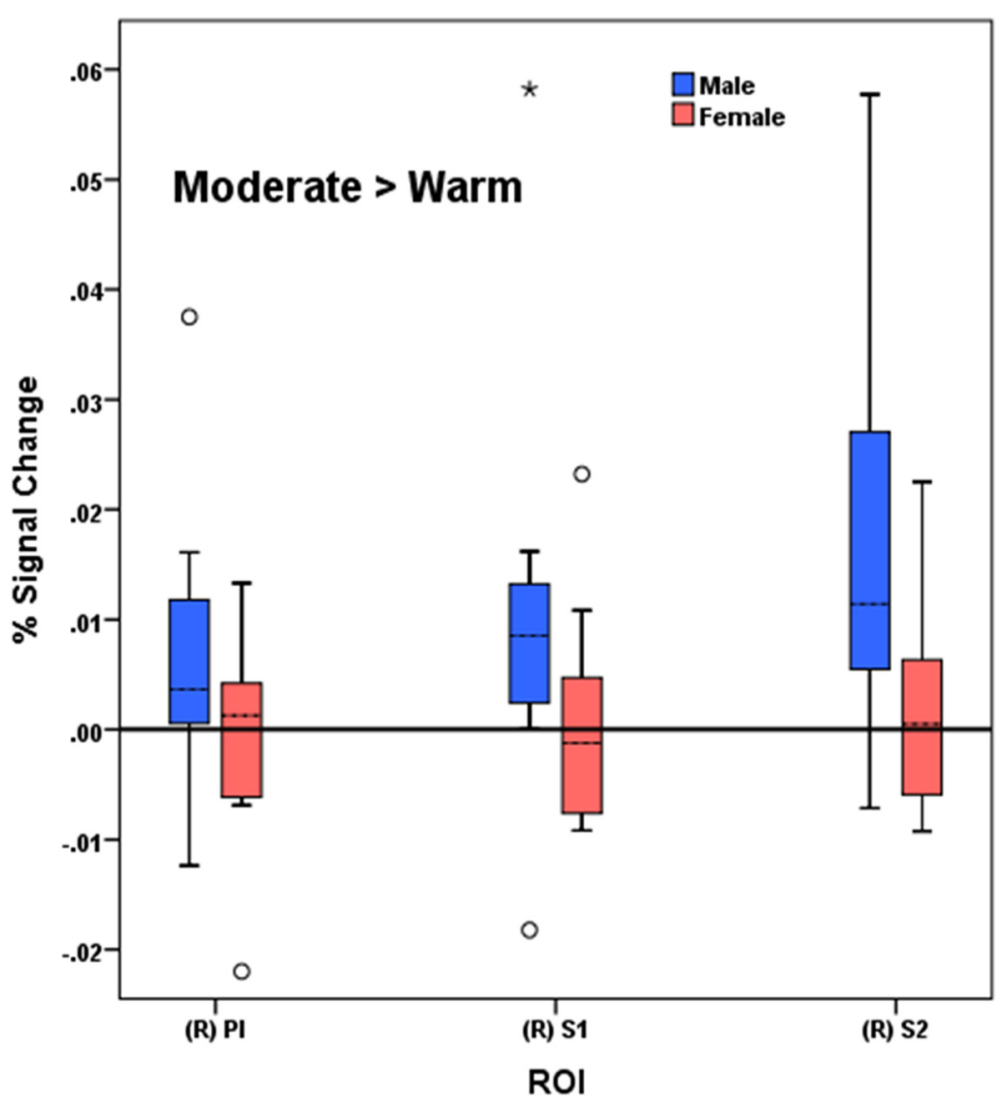

Fig. 11 Moderate > warm percent signal change values by sex. Between-group percent signal change values by sex for pain regions of interest in the moderate > warm contrast condition. pINS posterior insula, S/ primary somatosensory cortex, SII secondary somatosensory cortex

\section{Additional files}

Additional file 1: Figure S1. Females only. One-sample results for females only. Significant clusters were defined as those having a voxel level $p=0.05$, cluster volume 1659 voxels, and family wise error corrected $p=0.05$. The upper row displays brain deactivation to the contrast of mild pain > baseline, and the second row displays brain activation to the contrast of moderate pain $>$ baseline. Number next to the first image in each row indicates slice position relative to the AC/PC midline. Axia spacing $=4 \mathrm{~mm}$. Colorbar represents $T$ score intensity for each contrast. (TIF $443 \mathrm{~kb}$ )

Additional file 2: Figure S2. Males only. One-sample results for males only. Significant clusters were defined as those having a voxel level $p=0.05$, cluster volume 1659 voxels, and family wise error corrected $p=0.05$. The upper row displays brain activation to the contrast of mild pain $>$ baseline, and the second row displays brain activation to the contrast of moderate pain > baseline. Number next to the first image in each row indicates slice position relative to the AC/PC midline. Axial spacing $=4 \mathrm{~mm}$. Colorbar represents $T$ score intensity for each contrast. (TIF $389 \mathrm{~kb}$ )

\section{Abbreviations}

a: anterior; ACC: anterior cingulate cortex; BOLD: blood oxygenation level dependent; BPI: Brief Pain Inventory; d: dorsal; dl: dorsolateral;

DM: dorsomedial; DMN: default mode network; DRS: Dementia Rating Scale; EPI: echo planer image; f: functional; FC: functional connectivity; FG: fusiform gyrus; FOV: field of view; FWHM: full-width half-maximum; GDS: Geriatric Depression Scale; GLM: general linear model; HIPPO: hippocampus;
INS: insula; IQR: inter-quartile range; MMSE: Mini-Mental State Exam; MNI: Montreal Neurological Institute; MRI: magnetic resonance imaging; p: posterior; PAG: periaqueductal gray; PCG: posterior cingulate gyrus; PET: positron emission tomography; PFC: prefrontal cortex; r: rostral; ROI: region of interest; SES: socioeconomic status; sg: subgenual; SI: primary somatosensory; SII: secondary somatosensory; SMA: somatomotor area; STAI: State-Trait Anxiety Inventory; T: Tesla; TE: echo time; TFE: time of flight echo; TR: time to repeat; VPL: ventral posterolateral.

\section{Competing interests}

The authors declare that they have no competing interests.

\section{Authors' contributions}

All authors made substantial contributions to the work presented in this paper, as well as to the preparation of the paper itself. As Principal Investigator for this study, TM contributed to all stages including conception and design of the study, acquisition of study data, and analysis and interpretation of the data; drafting the article and revising for important intellectual content; and final approval of the version to be submitted. RC, $J G, S B$, and MD were integral to the conception and design of the study as well as the analysis and interpretation of the data. MB, LC, PN, JUB, RF, and BAC contributed significantly to all stages with particular focus on analysis and interpretation of the data. JA and SA assisted with data collection in addition to the drafting and revising of this article. All authors have approved the final article being submitted.

\section{Acknowledgements}

Funding sources for this project include The John A. Hartford Foundation, Mayday Fund, Vanderbilt Office of Clinical and Translational Scientist Development, Vanderbilt Clinical and Translational Research Scholars 
Program, and the NIH National Institute on Aging (1R21AG045735-01A1). The contents are solely the responsibility of the authors and do not necessarily represent the official views of these institutions. Study data were collected and managed using REDCap electronic data capture tools hosted at Vanderbilt University. REDCap is supported by Vanderbilt Institute for Clinical and Translational Research grant UL1 TR000011 from NCATS/NIH. The authors would also like to acknowledge Drs. Harry Gwirtsman, Manus Donahue, Elizabeth Stringer, and Langting Su for their work on this project, as well as Jessica Harbison for assisting with the preparation of this manuscript.

\section{Author details}

${ }^{1}$ Vanderbilt Psychiatric Neuroimaging Program, Vanderbilt University School of Nursing, Vanderbilt University Institute of Imaging Science, Nashville, TN, USA. ${ }^{2}$ Vanderbilt University Institute of Imaging Science, School of Medicine, Nashville, TN, USA. ${ }^{3}$ Vanderbilt University School of Medicine, Nashville, TN, USA. ${ }^{4}$ Vanderbilt Psychiatric Neuroimaging Program, School of Medicine, Vanderbilt University Institute of Imaging Science, Vanderbilt University School of Medicine, Nashville, TN, USA. ${ }^{5}$ Vanderbilt Center for Cognitive Medicine, Vanderbilt University School of Medicine, Nashville, TN, USA. ${ }^{6}$ University of Florida Pain Research and Intervention Center of Excellence, University of Florida College of Dentistry, Gainesville, FL, USA. Vanderbilt Memory and Alzheimer's Center, Vanderbilt University Institute of Imaging Science, Nashville, TN, USA.

Received: 28 July 2015 Accepted: 29 October 2015 Published online: 16 November 2015

\section{References}

1. The problem with pain [http://www.painfoundation.org/get-involved/ problem-with-pain.html]

2. Simon LS. Relieving pain in America: A blueprint for transforming prevention, care, education, and research. J Pain Palliat Care Pharmacother 2012;26(2):197-8. doi:10.3109/15360288.2012.678473.

3. Edwards RR, Fillingim RB, Ness TJ. Age-related differences in endogenous pain modulation: A comparison of diffuse noxious inhibitory controls in healthy older and younger adults. Pain. 2003;101(1-2):155-65.

4. Naugle KM, Cruz-Almeida Y, Fillingim RB, Riley 3rd JL. Offset analgesia is reduced in older adults. Pain. 2013;154(11):2381-7. doi:10.1016/ j.pain.2013.07.015.

5. Riley 3rd JL, King CD, Wong F, Fillingim RB, Mauderli AP. Lack of endogenous modulation and reduced decay of prolonged heat pain in older adults. Pain. 2010;150(1):153-60. doi:10.1016/j.pain.2010.04.020.

6. Fillingim RB, King CD, Ribeiro-Dasilva MC, Rahim-Williams B, Riley 3rd JL. Sex, gender, and pain: A review of recent clinical and experimental findings. J Pain. 2009;10(5):447-85. doi:10.1016/j.jpain.2008.12.001.

7. Johannes CB, Le TK, Zhou X, Johnston JA, Dworkin RH. The prevalence of chronic pain in United States adults: Results of an Internet-based survey. J Pain. 2010;11(11):1230-9. doi:10.1016/j.jpain.2010.07.002.

8. Leveille SG, Zhang Y, McMullen W, Kelly-Hayes M, Felson DT. Sex differences in musculoskeletal pain in older adults. Pain. 2005;116(3):332-8. doi:10.1016/j.pain.2005.05.002.

9. Ruau D, Liu LY, Clark JD, Angst MS, Butte AJ. Sex differences in reported pain across 11,000 patients captured in electronic medical records. J Pain. 2012;13(3):228-34. doi:10.1016/j.jpain.2011.11.002

10. Apkarian AV, Bushnell MC, Treede RD, Zubieta JK. Human brain mechanisms of pain perception and regulation in health and disease. Eur J Pain. 2005;9(4):463-84. doi:10.1016/j.ejpain.2004.11.001.

11. Davis K. fMRI of clinical pain. In: Faro SH, Mohamed FB, editors. Functional MRI: Basic Principles and Clinical Applications. New York: Springer; 2006.

12. Dosenbach NU, Visscher KM, Palmer ED, Miezin FM, Wenger KK, Kang HC, et al. A core system for the implementation of task sets. Neuron. 2006;50(5):799-812. doi:10.1016/j.neuron.2006.04.031.

13. Treede RD, Kenshalo DR, Gracely RH, Jones AK. The cortical representation of pain. Pain. 1999;79(2-3):105-11.

14. Menon V, Uddin LQ. Saliency, switching, attention and control: a network model of insula function. Brain Struct Funct. 2010;214(5-6):655-67. doi:10.1007/s00429-010-0262-0.

15. Craig AD. How do you feel-now? The anterior insula and human awareness. Nat Rev Neurosci. 2009;10(1):59-70. doi:10.1038/nrn2555.
16. Oertel BG, Preibisch C, Martin T, Walter C, Gamer M, Deichmann R, et al. Separating brain processing of pain from that of stimulus intensity. Hum Brain Mapp. 2012;33(4):883-94. doi:10.1002/hbm.21256.

17. Tracey I, Leknes S. Hippocampus and entorhinal complex: Functional imaging. In: Gebhart G, Schmidt R, editors. Encyclopedia of Pain. Berlin Heidelberg: Springer; 2013. p. 1476-81.

18. Tracey I, Mantyh PW. The cerebral signature for pain perception and its modulation. Neuron. 2007;55(3):377-91. doi:10.1016/j.neuron.2007.07.012

19. Wager TD, Atlas LY, Lindquist MA, Roy M, Woo CW, Kross E. An fMRI-based neurologic signature of physical pain. N Engl J Med. 2013;368(15):1388-97. doi:10.1056/NEJMoa1204471.

20. Paulson PE, Minoshima S, Morrow TJ, Casey KL. Gender differences in pain perception and patterns of cerebral activation during noxious heat stimulation in humans. Pain. 1998;76(1-2):223-9.

21. Straube T, Schmidt S, Weiss T, Mentzel HJ, Miltner WH. Sex differences in brain activation to anticipated and experienced pain in the medial prefrontal cortex. Hum Brain Mapp. 2009;30(2):689-98. doi:10.1002/ hbm.20536.

22. Wang G, Erpelding N, Davis KD. Sex differences in connectivity of the subgenual anterior cingulate cortex. Pain. 2014;155(4):755-63. doi:10.1016/j.pain.2014.01.005

23. Folstein MF, Folstein SE, McHugh PR. "Mini-Mental State": A practical method for grading the cognitive state of patients for the clinician. J Psychiatr Res. 1975;12(3):189-98.

24. Fillingim RB, Edwards RR. The association of hormone replacement therapy with experimental pain responses in postmenopausal women. Pain. 2001;92(1-2):229-34.

25. Riley 3rd JL, Gilbert GH, Heft MW. Socioeconomic and demographic disparities in symptoms of orofacial pain. J Public Health Dent. 2003;63(3):166-73.

26. Hollingshead AB. Four factor index of social status. New Haven: Yale University, Department of Sociology; 1975.

27. Jurica PJ, Leitten CL, Mattis S. DRS-2 Dementia Rating Scale-2: Professional manual: Psychological Assessment Resources; 2004.

28. Keller S, Bann CM, Dodd SL, Schein J, Mendoza TR, Cleeland CS. Validity of the Brief Pain Inventory for use in documenting the outcomes of patients with noncancer pain. Clin J Pain. 2004;20(5):309-18.

29. Friedman B, Heisel MJ, Delavan RL. Psychometric properties of the 15-item Geriatric Depression Scale in functionally impaired, cognitively intact, community-dwelling elderly primary care patients. J Am Geriatr Soc. 2005;53(9):1570-6. doi:10.1111/j.1532-5415.2005.53461.x.

30. Kval K, Ulstein I, Nordhus IH, Engedal K. The Spielberger State-Trait Anxiety Inventory (STAI): the state scale in detecting mental disorders in geriatric patients. Int J Geriatr Psychiatry. 2005;20(7):629-34. doi:10.1002/gps.1330.

31. Cole LJ, Farrell MJ, Duff EP, Barber JB, Egan GF, Gibson SJ. Pain sensitivity and $\mathrm{fMRI}$ pain-related brain activity in Alzheimer's disease. Brain. 2006;129(Pt 11):2957-65. doi:10.1093/brain/awl228.

32. Medoc Advanced Medical Systems. Pathway Pain \& Sensory Evaluation System. Durham, NC: Medoc Ltd. Advanced Medical Systems; 2006. p. 3.

33. Price DD, McGrath PA, Rafii A, Buckingham B. The validation of visual analogue scales as ratio scale measures for chronic and experimental pain. Pain. 1983;17(1):45-56.

34. Petzke F, Gracely RH, Park KM, Ambrose K, Clauw DJ. What do tender points measure? Influence of distress on 4 measures of tenderness. J Rheumatol. 2003;30(3):567-74.

35. Woo CW, Krishnan A, Wager TD. Cluster-extent based thresholding in fMRI analyses: pitfalls and recommendations. Neuroimage. 2014;91:412-9. doi:10.1016/j.neuroimage.2013.12.058.

36. Brett $M$, Anton J, Valabregue R, Poline J: Region of interest analysis using an SPM toolbox [abstract]. In: 8th International Conference on Functional Mapping of the Human Brain: 2002; Sendai, Japan: Neuroimage; 2002.

37. Buckner RL, Andrews-Hanna JR, Schacter DL. The brain's default network: anatomy, function, and relevance to disease. Ann N Y Acad Sci. 2008;1124:1-38. doi:10.1196/annals.1440.011.

38. Kong J, Loggia ML, Zyloney C, Tu P, Laviolette P, Gollub RL. Exploring the brain in pain: activations, deactivations and their relation. Pain. 2010;148(2):257-67. doi:10.1016/j.pain.2009.11.008.

39. Greicius MD, Menon V. Default-mode activity during a passive sensory task: uncoupled from deactivation but impacting activation. J Cogn Neurosci. 2004;16(9):1484-92. doi:10.1162/0898929042568532. 
40. Bantick SJ, Wise RG, Ploghaus A, Clare S, Smith SM, Tracey I. Imaging how attention modulates pain in humans using functional MRI, vol. 125; 2002.

41. Derbyshire SW, Nichols TE, Firestone L, Townsend DW, Jones AK. Gender differences in patterns of cerebral activation during equal experience of painful laser stimulation. J Pain. 2002;3(5):401-11.

42. Deen B, Pitskel NB, Pelphrey KA. Three systems of insular functional connectivity identified with cluster analysis. Cereb Cortex. 2011;21(7):1498-506. doi:10.1093/cercor/bhq186.

43. Farrell MJ. Age-related changes in the structure and function of brain regions involved in pain processing. Pain Med. 2012;13 Suppl 2:S37-43. doi:10.1111/j.1526-4637.2011.01287.x.

44. Hamm RJ, Knisely JS. Environmentally induced analgesia: an age-related decline in an endogenous opioid system. J Gerontol. 1985;40(3):268-74.

45. Hess GD, Joseph JA, Roth GS. Effect of age on sensitivity to pain and brain opiate receptors. Neurobiol Aging. 1981;2(1):49-55.

46. Washington LL, Gibson SJ, Helme RD. Age-related differences in the endogenous analgesic response to repeated cold water immersion in human volunteers. Pain. 2000;89(1):89-96.

47. Zubieta JK, Dannals RF, Frost JJ. Gender and age influences on human brain mu-opioid receptor binding measured by PET. Am J Psychiatry. 1999;156(6):842-8

48. Bencherif B, Fuchs PN, Sheth R, Dannals RF, Campbell JN, Frost JJ. Pain activation of human supraspinal opioid pathways as demonstrated by [11C]-carfentanil and positron emission tomography (PET). Pain. 2002;99(3):589-98.

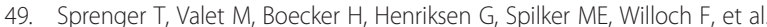
Opioidergic activation in the medial pain system after heat pain. Pain. 2006;122(1-2):63-7. doi:10.1016/j.pain.2006.01.003.

50. Zubieta J-K, Smith YR, Bueller JA, Xu Y, Kilbourn MR, Jewett DM, et al. Regional mu opioid receptor regulation of sensory and affective dimensions of pain. Science. 2001:293(5528):311-5. doi:10.1126/science.1060952.

51. Zubieta JK, Smith YR, Bueller JA, Xu Y, Kilbourn MR, Jewett DM, et al Mu-opioid receptor-mediated antinociceptive responses differ in men and women. J Neurosci. 2002;22(12):5100-7.

52. Price DD. Psychological and neural mechanisms of the affective dimension of pain. Science. 2000;288(5472):1769-72.

53. Rainville $P$, Duncan GH, Price DD, Carrier B, Bushnell MC. Pain affect encoded in human anterior cingulate but not somatosensory cortex. Science. 1997;277(5328):968-71.

54. Bingel U, Quante M, Knab R, Bromm B, Weiller C, Buchel C. Single trial fMRI reveals significant contralateral bias in responses to laser pain within thalamus and somatosensory cortices. Neuroimage. 2003;18(3):740-8.

55. Chakour MC, Gibson SJ, Bradbeer M, Helme RD. The effect of age on A delta- and C-fibre thermal pain perception. Pain. 1996;64(1):143-52.

56. Gøransson L, Mellgren S, Lindal S, Omdal R. The effect of age and gender on epidermal nerve fiber density. Neurology. 2004;62(5):774-7.

57. Edwards RR. Individual differences in endogenous pain modulation as a risk factor for chronic pain. Neurology. 2005:65(3):437-43. doi:10.1212/ 01.wnl.0000171862.17301.84.

\section{Submit your next manuscript to BioMed Central and take full advantage of:}

- Convenient online submission

- Thorough peer review

- No space constraints or color figure charges

- Immediate publication on acceptance

- Inclusion in PubMed, CAS, Scopus and Google Scholar

- Research which is freely available for redistribution

Submit your manuscript at www.biomedcentral.com/submit 